\title{
EL TERREMOTO DEL 4 DE MARZO DE 1924 (Ms 7,0): ¿UN GRAN TEMBLOR INTERPLACA RELACIONADO AL LÍMITE INCIPIENTE ENTRE LA PLACA CARIBE Y LA MICROPLACA DE PANAMÁ?
}

\author{
Walter Montero P. \\ Escuela Centroamericana de Geología, Universidad de Costa Rica \\ Apartado 35-2060 \\ E-mail:wmontero@cariari.ucr.ac.cr
}

(Recibido 4/11/1998; Aceptado 17/2/1999)

\begin{abstract}
The seismogenic source, the intensity distribution and the coseismic effects are investigated for the March 4, 1924 (Ms = 7.0) earthquake, which occurred in the central-pacific forearc of Costa Rica. A neotectonic study allows to define the characteristics of the cortical faulting related to this destructive earthquake. From a careful study of macroseismic data obtained from different bibliographic sources, the intensity distribution of this earthquake is defined. Maximum intensities between VIII and IX in the Mercalli Modified scale were defined in the mesoseismal area, which includes the towns of Orotina, San Mateo, San Ramón and Esparza. The earthquake produce the collapse and damage of a great number of houses and buildings, strong damage to the railroad, great number of landslides, rock falls, earth cracks and liquefaction. The earthquake aftershock sequence includes various events with magnitudes Ms between 5.0 and 6.4. The main shock triggered seismic activity in different faults along the interior region of the country, and eruptions at the Irazú and Rincón de la Vieja volcanoes.

With criteria such as an epicentral location using regional seismographic stations, the trend of the $\mathrm{S}$ wave and the S-P from aftershocks, the mesoseismal area, and a possible earthquake rupture, it is suggested that the seismogenic source of the earthquake was the Tárcoles fault, although it is believed that the Bijagual fault system also contribute to the rupture process. These are transcurrent faults trending NE to N, that belong to a deformation zone located between the Caribbean plate and the Panamá microplate. For this reason, the March 4, 1924 earthquake is considered an interplate event related to the incipient limit between those tectonic plates.
\end{abstract}

RESUMEN: La fuente sismogénica, la distribución de intensidades y los efectos cosísmicos son investigados para el terremoto del 4 de marzo de 1924 (Ms =7,0), ocurrido en la región del antearco central pacífico de Costa Rica. Un estudio neotectónico permite identificar las características del fallamiento cortical al cual se asocia este destructivo sismo. Un estudio cuidadoso de datos macrosísmicos recopilados de diferentes fuentes bibliográficas ha permitido determinar la distribución de intensidades de este evento, el cual originó intensidades Mercalli Modificada (MM) entre VIII y IX grados en el área mesosísmica, que incluye entre otros a los poblados de Orotina, San Mateo, San Ramón y Esparza. Aparte del gran número de casas y edificios que quedaron inhabitables, el terremoto generó innumerables daños a la línea férrea, gran cantidad de deslizamientos, caída de rocas, agrietamientos del suelo y licuefacción. El terremoto fue seguido por varias réplicas con magnitudes Ms entre 5,0 y 6,4. Además, el evento principal disparó actividad sísmica en varias fallas corticales del interior del país y actividad volcánica en el Irazú y posiblemente en el Rincón de la Vieja.

De acuerdo con diversos criterios como son una localización epicentral con estaciones sismológicas regionales, la dirección de la onda S y el S-P de las réplicas, el área mesosísmica y una posible ruptura superficial, se sugiere que la fuente sismogénica de este terremoto fue la falla Tárcoles, aunque el sistema de falla Bijagual, también debió participar en el proceso de ruptura. Estas son fallas transcurrentes de rumbo NE a N, que forman parte de la zona de deformación que sirve de límite entre la placa del Caribe y la microplaca de Panamá, por lo que este evento se considera un sismo interplaca relacionado al límite incipiente entre las anteriores unidades tectónicas. 


\section{INTRODUCCIÓN}

El terremoto de San Casimiro del 4 de marzo de 1924, de las 10 h y 07 min GMT (Ms $7,0)$, ha sido uno de los terremotos más destructivos ocurridos en Costa Rica a través de su historia, debido a que generó daños de alta intensidad en una gran región que incluyó Orotina, San Mateo, Esparza en la región pacífica central y algunas de las principales ciudades del Valle Central como fueron San Ramón, Atenas, Palmares, Grecia, Alajuela, Heredia y el mismo San José. En la Tribuna del 29 de marzo (página 3) se reporta que las pérdidas que causó este sismo fueron por $\notin 30$ millones de colones. El temblor fue sentido en toda Costa Rica y en gran parte de Nicaragua y Panamá.

Varios son los aspectos del terremoto de 1924 que no han sido estudiados en detalle hasta ahora. Entre estos destacan su fuente sismogénica, la secuencia sísmica asociada, incluyendo la sismicidad que el evento principal disparó en la zona central del país, las intensidades alcanzadas y el patrón de intensidades del evento principal.

Con respecto al origen de este sismo, demostraremos que este evento se asoció al sistema de fallas corticales que se ubican en el límite entre la placa Caribe y la microplaca de $\mathrm{Pa}$ namá y no se relacionó con la zona interplaca Coco-Caribe. Un origen de este sismo en una falla cortical había sido sugerido previamente por Montero \& Dewey (1982), Jacob et al. (1991) y Montero (1994a), aunque una demostración adecuada de este aspecto no ha sido aún realizada.

En este estudio se dedicará una especial atención a la definición de la fuente sismogénica del sismo de 1924. Pero también se le dará importancia a la determinación de la distribución de intensidades, detallando la zona donde se concentró la mayor destrucción, la secuencia sísmica asociada, algunos efectos cosísmicos y finalmente la importancia que este tipo de eventos tienen para la adecuada evaluación de la amenaza sísmica de la región central del país.

\section{METODOLOGÍA}

\section{Estudio neotectónico}

Se aplicó la siguiente metodología en el estudio neotectónico de la región del pacífico central:

1. Interpretación neotectónica con base en fotos aéreas y de imágenes de radar de diferentes escalas. Como resultado se elaboró un mapa de lineamientos sugestivos de ser fallas recientes de la zona de interés.

2. Revisión bibliográfica sobre la neotectónica de la zona marina y continental. Incluye una revisión de la sismicidad histórica y especialmente de la reciente, para definir su correlación con lineamientos y fallas cartografiadas.

3. Estudio neotectónico de campo que consistió en visitas a la zona para definir la naturaleza de algunos de los principales lineamientos definidos en el punto uno, especialmente si correspondían o no con fallas neotectónicas. En esta fase, además de reconocer y caracterizar con mayor detalle los elementos geomórficos observados en las fotos aéreas, se visitaron afloramientos en quebradas, ríos, caminos, etc, que permitieran confirmar o descartar la presencia de las fallas y sus características estructurales.

4. Elaboración final del mapa sintético del fallamiento neotectónico del antearco central pacífico de Costa Rica, incluyendo los diversos datos obtenidos a partir de los puntos anteriores. En este mapa se clasifican las estructuras en fallas neotectónicas y lineamientos sugestivos de ser fallas neotectónicas.

\section{Estimación de intensidades y determinación de isosistas}

La estimación de intensidades y el mapa de distribución de isointensidades, resultó de datos macrosísmicos obtenidos de los periódicos 
La Nueva Prensa, La Prensa, La Gaceta (periódico oficial), El Diario de Costa Rica, La Tribuna, La Voz, y La Noticia. La estimación de la intensidad resultó del análisis de los informes recopilados en los diferentes periódicos. Además, para la región mesosísmica se realizaron entrevistas a personas que fueron testigos presenciales del terremoto, la cual fue útil para complementar los datos macrosísmicos recopilados en los periódicos. En varios casos, la incertidumbre existente en la información macrosísmica solo permitió estimar la intensidad entre dos valores sucesivos.

La información macrosísmica fue interpretada aplicando la escala Mercalli Modificada (MM). Para la determinación de las intensidades en zonas rurales, como fue el caso del terremoto de 1924, se consideraron los criterios de Dengler \& McPherson (1993). Además de los daños a construcciones se evaluaron efectos sobre el terreno como son deslizamientos de tierra o de roca, formación de grietas y licuefacción. También, se reportaron líneas ferroviarias dobladas, puentes destruídos, tuberías fuera de servicio, entre otros tipos de daños. Para las personas interesadas, el autor tiene un cuadro resúmen de las principales observaciones macrosísmicas entresacadas de los diferentes periódicos consultados y las entrevistas personales realizadas.

\section{NEOTECTÓNICA, SISMICIDAD Y SISMOTECTÓNICA DEL ANTEARCO CENTRAL DE COSTA RICA}

El terremoto del 4 de marzo de 1924 ocurrió en una zona sismológica y tectónicamente compleja, tanto con relación a las características geométricas de la placa del Coco que se esta subduciendo, como con respecto a la configuración tectónica de las placas cabalgantes. Estas las describimos a continuación.

\section{La zona de interacción de placas}

Frente a la costa pacífica de Costa Rica y a partir de la Fosa Mesoamericana, la placa del Coco se subduce con respecto a la placa Caribe, hacia el $\mathrm{N} 30^{\circ} \mathrm{E}$ a una velocidad entre 9 y 10 $\mathrm{cm} /$ año (Fig. 1). En esta región, la batimetría de la placa del Coco presenta diversos elementos morfoestructurales. Al sur de la Península de Nicoya, la placa del Coco acarrea hacia la fosa, la frontera rugosa-suave (FRS), la cual divide a la placa del Coco en una zona de batimetría bastante suave hacia el NW, de una zona de colinas submarinas hacia el SE (Fig. 1). La FRS se forma en el punto triple Coco-Nazca-Pacífico. El sector sureste de la misma se origina en la Dorsal de Las Galápagos a una velocidad de acreción entre 5 y $7 \mathrm{~cm} / a n ̃ o$, mientras que el sector norte se forma en la Dorsal del Pacífico Este, a una velocidad de acreción de alrededor de $13 \mathrm{~cm} /$ año (Lonsdale \& Klitgord, 1978). Por lo tanto, el límite rugoso-suave constituye una zona de cambio de la morfología submarina, que a su vez corresponde con una zona de diferencia de la edad del basamento oceánico (Protti et al, 1995a): más jóven al sureste y más viejo al noroeste. Al sureste del límite FRS, la placa del Coco subduce una serie de colinas submarinas de rumbo NE, que originan cicatrices del lado interno de la fosa de un rumbo paralelo a la dirección de convergencia (von Huene et al, 1995).

\section{El fallamiento cortical del antearco central}

Existen varias fallas neotectónicas relevantes en el antearco central de Costa Rica. En la zona continental, comprendida entre Orotina y Esparza, el sistema de fallas tiene rumbo NE a E (Fig. 2), con algunos trechos cortos de rumbo NS. Las fallas más importantes de este sistema son las fallas Barranca, Mata de Limón, Jesús María y Tárcoles (Madrigal, 1970; Fisher et al, 1994; Montero, 1994a; Fisher et al, 1998). Las fallas Barranca, Jesús María y Tárcoles tienen un movimiento oblicuo combinando desplazamiento sinestral con normal (Fisher et al., 1994; 


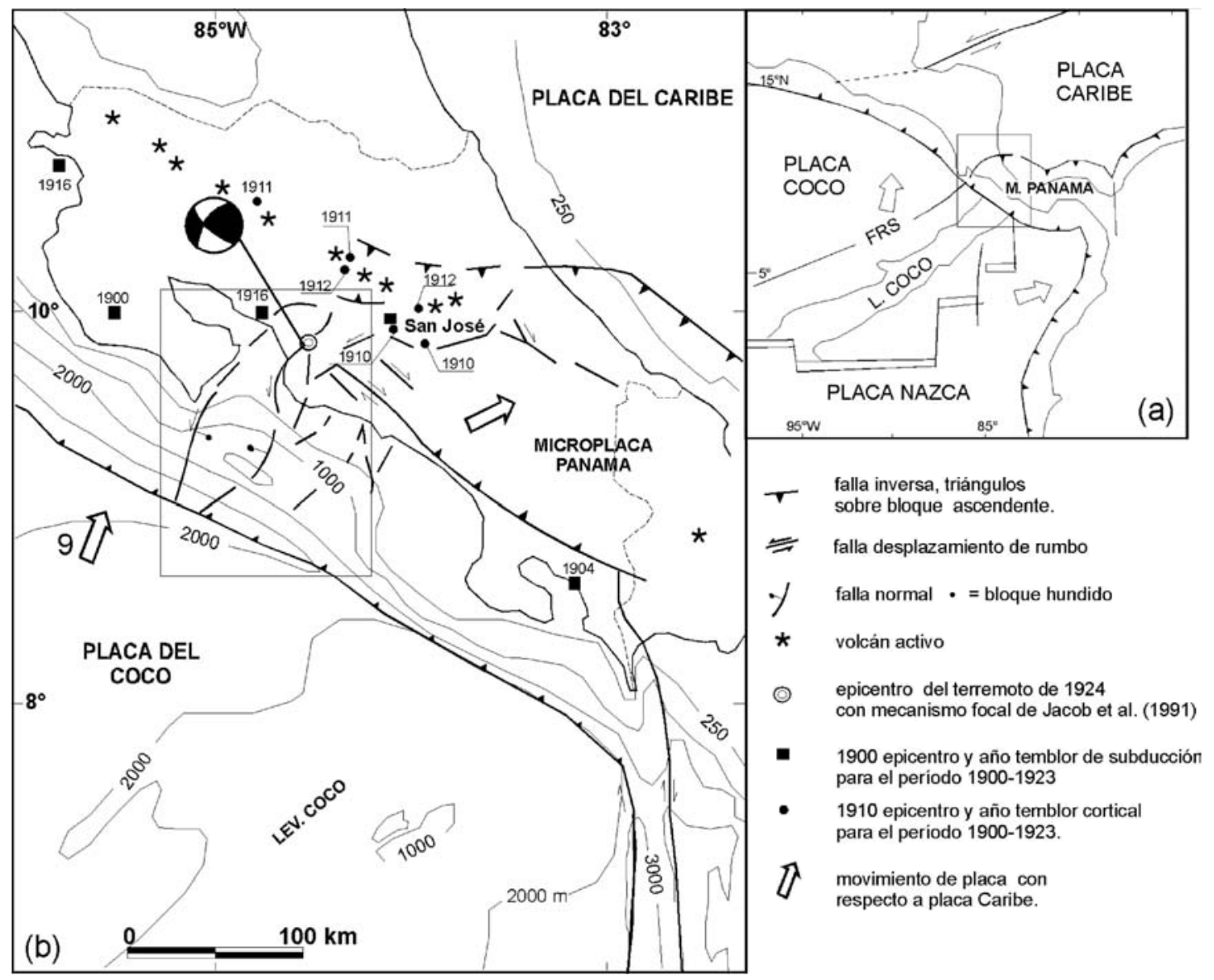

Fig. 1: (a) Marco tectónico regional. Se observa la microplaca Panamá con relación a las otras placas. FRS es la frontera rugosa-suave que se subduce frente a la entrada de la Península de Nicoya. (b) Marco tectónico de Costa Rica. Se observa el sistema de fallamiento difuso que sirve de límite entre la microplaca de Panamá y la placa Caribe y que atravieza Costa Rica transversalmente. Obsérvese como el vector de movimiento relativo entre las placas Coco y Caribe $(9 \mathrm{~cm} / \mathrm{año})$ y el vector de deslizamiento deducido para el terremoto de Limón por Goes et al. (1993), difieren en su rumbo. Este último correspondería con el deslizamiento entre la placa Caribe y la microplaca de Panamá.

Marshall, 1994; Fisher et al., 1998). Fischer (1980) usando superficies bioerosionales, definió una serie de zonas de levantamiento y hundimiento a lo largo del margen pacífico central, que se relacionan con fallas transversales a la costa, como serían las fallas Barranca, Jesús María y Tárcoles. Madrigal (1970) llamó la atención acerca del rejuvenecimiento geomorfológico de la región de Esparza-Orotina. Fisher et al. (1998) y Sak et al. (1997) consideran que la ubicación y movimiento de estas fallas es controlada por la subducción de las cadenas de montañas submarinas de rumbo $\mathrm{NE}$, que son acarreadas por la placa del Coco bajo el antearco central (von Huene et al., 1995).

Por otro lado, dentro del Promontorio de Herradura, del lado oeste del Cerro Turrubares, se presenta otro sistema de fallas, el cual denominamos como el sistema de fallas de Bijagual. Estas tienen un rumbo predominante NS, con la excepción de la falla Tulín, que tiene un rumbo ENE. Estas fallas han sido menos estudiadas, 


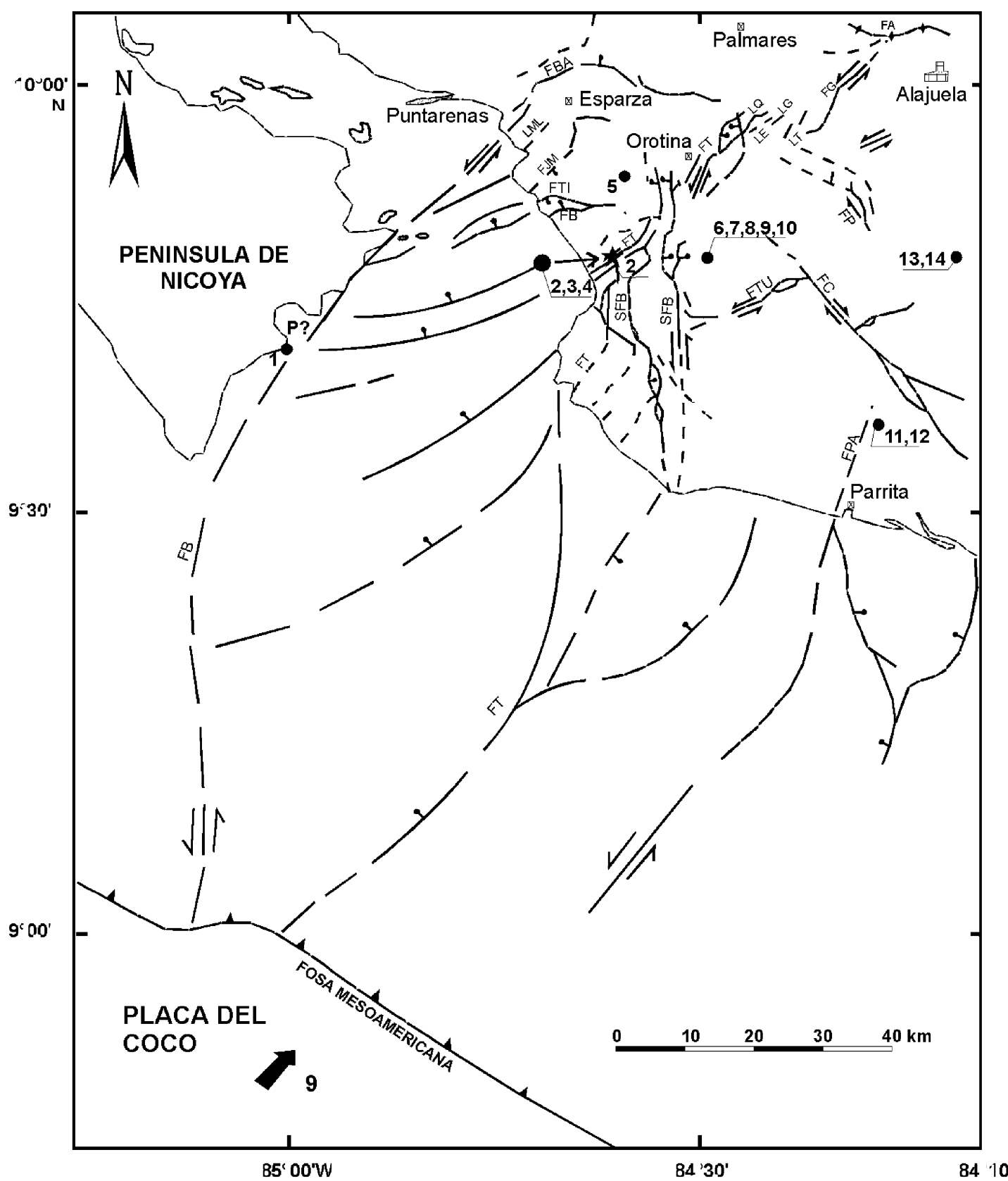

Fig. 2: Sistema de fallamiento cortical del antearco central de Costa Rica. Simbología de las fallas se explica en la figura 1. En la zona continental se muestran a trazos los lineamientos sugestivos de ser fallas recientes. Las que se ubican en el lado marino son de Fernández et al. (1997). Los círculos rellenos son los epicentros de Ambraseys (1995). Se ubica con una estrella el epicentro escogido para el evento principal en este trabajo, el cual esta desplazado al este con respecto al de Ambraseys (1995). El número al lado del epicentro señala el asignado en el cuadro 1. Para el probable evento precursor (No 1) se indica un signo de interrogación señalando la duda de que este ocurrió dentro de la zona de ruptura de 1924. FBA: falla Barranca, LML: lineamiento Mata de Limón, FJM: falla Jesús María, FTI: falla Tivives, FB: falla Bajamar, FT: falla Tárcoles, SFB: sistema de falla Bijagual, LQ, LE, LG y LT: lineamientos Quebradas, Escobal, Guácimos y Tornos respectivamente, FG: falla Garita, FA: falla Alajuela, FTU: falla Tulín, FC: falla candelaria y FP: falla Picagres. FPA: falla Parrita deducida de Fisher et al. (1998). 
aunque por su prominencia en las imágenes de sensores remotos y su posible correlación con la sismicidad reciente, parecen estar activas.

Montero (1994a) estima que los anteriores sistemas de fallas definen el límite entre la placa del Caribe y la microplaca de Panamá. La microplaca de Panamá, que se ubica al sur de esta zona de cizalle, se desplaza relativamente hacia el NE con respecto a la placa del Caribe, originando desplazamiento sinestral y tracción en la región central pacífica de Costa Rica (Montero, 1994a).

En la figura 3 mostramos el fallamiento cortical del antearco central superpuesto con la sismicidad de profundidad menor a $20 \mathrm{~km}$, para el período 03/1997 a 01/1998. Los temblores fueron localizados con una red de estaciones sismológicas temporales que complementó las de la Red Sismológica Nacional (RSN), que incluye datos del Instituto Costarricense de Electricidad (ICE) y de la Universidad de Costa Rica (UCR). La anterior información sismológica proviene de un estudio de Montero et al. (en preparación). Esta figura permitirá aclarar la sismicidad de algunas de las fallas que se discuten a continuación.

\section{Falla Barranca}

La falla Barranca (FBA) parece iniciarse con rumbo NE en el área marina (Fernández et al., 1997) y se continuaría en el continente, con una traza que sigue un rumbo paralelo al cauce del río Barranca (Madrigal, 1970; Fischer, 1980; Fisher et al., 1994; Montero, 1994a; Fisher et al., 1998), hasta entrar en los cerros del Aguacate donde toma un rumbo cercano al EW. Mi interpretación indica que se inicia en el área continental al sureste de Puntarenas, en la zona de la desembocadura del Río Barranca (Fig. 2). Esto es corroborado por los datos de las plataformas bioerosionales levantadas encontradas por Fischer (1980). Once kilómetros aguas arriba de la desembocadura del Río Barranca, la terraza El Diablo, que tiene una edad máxima de 1,2 M.a., subió $30 \mathrm{~m}$ del lado sureste de esta falla (Fisher et al., 1994). Marshall (1994) estima que las terrazas y las tobas soldadas cuaternarias, muestran una separación vertical entre 10 y 50 metros a lo largo de la falla Barranca. En los
Montes del Aguacate, mi análisis neotectónico muestra que la falla Barranca cambia su rumbo entre el EW y el WNW.

Con respecto al tipo de desplazamiento, Madrigal (1970) propuso que la falla Barranca era normal. Sin embargo, los datos de Fisher et al. (1994) sugieren que esta falla combina desplazamiento normal con desplazamiento sinestral.

Con relación a la sismicidad y sismotectónica de esta falla, encontramos una secuencia de temblores registrada por la red de estaciones sismológicas de la UCR y del ICE, entre el 21 y 22 de junio de 1978. El temblor principal de la secuencia tuvo magnitud coda Mc 4,5. Los eventos tuvieron profundidades entre 10 y $15 \mathrm{~km}$ y se ubicaron muy cerca o sobre la traza de la falla Barranca, donde esta tiene rumbo EW, en los Montes del Aguacate. Posteriormente, Güendel et al. (1992) reportan un mecanismo focal compuesto para un grupo de temblores que se ubicó en las cercanías del poblado de Esparza. La solución es de fallamiento inverso con una componente transcurrente. De acuerdo con mi estudio neotectónico, la secuencia de Esparza se localizó muy cerca o sobre la traza de la falla Barranca. Finalmente, en la figura 3 observamos que varios temblores superficiales ocurridos entre marzo de 1996 y enero de 1998 fueron localizados cerca o muy cerca de la traza de esta falla, en la zona de Esparza. Esta sismicidad es estudiada con más detalle por Montero et al (en preparación).

\section{Lineamiento Mata de Limón}

El lineamiento Mata de Limón (LML) se iniciaría en el sector marino de la entrada del Golfo de Nicoya, según se deduce de estudios geofísicos (Astorga et al., 1991; Barboza et al., 1995; Fernández et al., 1997). En el sector continental, este lineamiento muestra un escarpe en el lado occidental, sugiriendo que el borde oriental, donde se ubica el estero de Mata de Limón, esta relativamente hundido. Este lineamiento puede continuarse al noreste con una falla que aparece en Madrigal (1970), la cual desplaza sinestralmente por unos 300 metros, un eje sinclinal de un pliegue de la formación miocénica de Punta Carballo. 


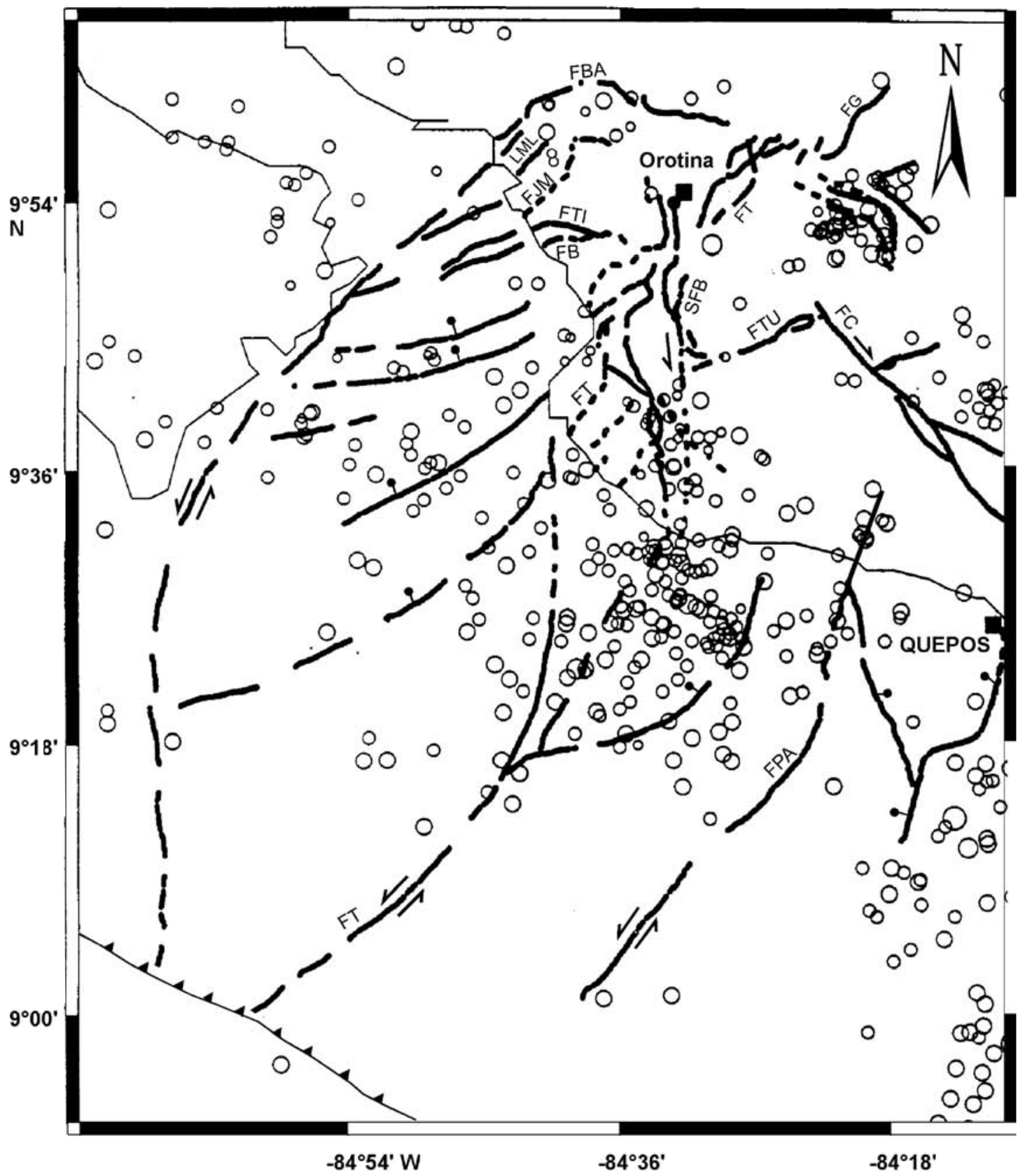

Fig. 3: Sismicidad para el período marzo de 1996 a enero de 1998, de profundidad menor a $20 \mathrm{~km}$ superpuesta con el fallamiento cortical (Montero et al., en preparación). Obsérvese la posible asociación entre ambos, aunque eventos relacionados con el proceso de subducción también están presentes. 


\section{Falla Jesús María}

La falla Jesús María (FJM) aparece por primera vez en Madrigal (1970), quien la considera una falla normal de alto ángulo. La falla Jesús María presenta un escarpe bastante disectado que mira al sureste. Sobre el bloque oriental, que se esta hundiendo, discurre el río Jesús María y se presentan varios esteros. A lo largo de esta falla, lahares del Cuaternario y del Terciario Tardío muestran una separación vertical, donde el lado noroeste de la falla sube aproximadamente $120 \mathrm{~m}$ (Fisher et al., 1994). Marshall (1994) considera que los lahares cuaternarios tienen una separación vertical de 80 metros. En el extremo NE, la falla tiene un cambio de rumbo hacia el E. Fisher et al. (1994) han denominado al bloque entre las fallas Barranca y la Jesús María, con el nombre de Esparza, el cual sería un bloque relativamente levantado.

\section{Sistema de fallas Tárcoles}

Es un sistema de fallas de rumbo predominante NE, pero que localmente presenta rumbos entre EW y NS. Tiene varios ramales entre los cuales se encuentran las fallas Tivives, Bajamar, Tárcoles, Pigres, Quebradas, Escobal, Guácimos y Tornos. La falla Tárcoles, que se considera activa, es la que tiene mayor longitud. Fue originalmente reconocida por Weyl (1961) y luego incorporada en el mapa geológico de Dóndoli et al. (1968). Posteriormente, Madrigal (1970) la cartografía con mayor detalle y la considera como una falla normal. Fischer (1980) y Fisher et al. (1994) fueron los primeros en reconocer sus carácter neotectónico. Marshall (1994) también describe desplazamientos neotectónicos en la fa1la. La traza que se define en este estudio es con base en criterios neotectónicos usando fotogeología y trabajo de campo.

\section{Fallas Tivives (FTI) y Bajamar (FB)}

Son dos trazas con rumbo cercano al EW, las cuales se inician en la zona costera, cerca de las localidades de Tivives y de Bajamar. Estas fallas parecen tener continuidad en la zona marina (Fig. 2). Ambas trazas muestran escarpes que definen una estructura tipo graben entre ellas. Al este ambas fallas se unen y se continúan con una sola traza antes de terminar contra la falla Tárcoles.

\section{La falla Tárcoles}

La falla Tárcoles (FT) se inicia en el área marina y se puede relacionar con una falla que parece desplazar sinestralmente el eje de la Fosa Mesoamericana (Corrigan et al., 1990; Astorga et al., 1991). También, puede corresponder con una falla que sería la traza central de la cuenca de tracción que se forma junto con la falla $\mathrm{Ba}$ rranca y con el sistema de falla Bijagual (discutida posteriormente).

Entra en el área continental alineándose con el río Grande de Tárcoles. En la desembocadura de este río, Fischer (comunicación personal, 1982) encontró plataformas de bioerosión hundidas, ahogadas, en diferentes niveles, lo cual indica bloques que se hundieron en forma escalonada. Se puede comprobar una subsidencia de un metro debajo del nivel originario. No observó mayor subsidencia porque las morfologías bioerosivas necesarias para evaluar ésta, fueron cubiertas por arena acumulada por el río en su desembocadura.

La falla presenta varias trazas. La traza oriental muestra un escarpe que mira al noroeste lo cual sugiere levantamiento del lado este de la falla. Esto es corroborado por Fisher et al. (1994; 1998). Depósitos de terrazas fluviales recientes que se localizan cerca de la desembocadura de este río, se muestran fallados a lo largo de la traza central. Al SSW de Orotina se encontraron depósitos aluviales recientes cortados por pequeñas fallas, a lo largo de una traza de esta falla (sitio 1 en Fig. 4). Al sur de Orotina, la falla Tárcoles se une con el sistema de fallas de Bijagual que tiene rumbo NS (Fig. 4). En este sector se observan varias trazas de rumbo NS, que forman un sistema de fallas normales. La falla Tárcoles continúa con una traza de rumbo NE, pasando al este de Orotina y de Hacienda Vieja y entra luego en los Montes del Aguacate, donde se divide en varios 


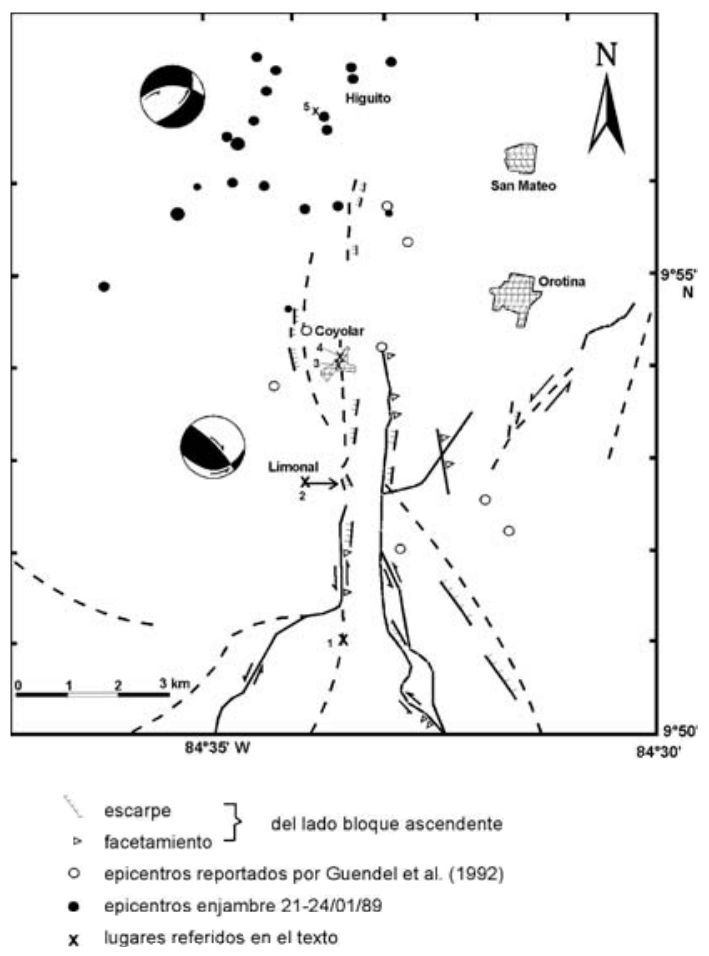

Fig. 4: Detalle de la zona de intersección entre las fallas Tárcoles y Bijagual. El mecanismo focal compuesto mostrado al oeste de Limonal fue obtenido por Güendel et al. (1992). El mecanismo focal compuesto mostrado al oeste de Higuito fue realizado por Güendel et al (1993).

ramales. En esta zona se define una estructura sigmoidal transtensiva limitada por dos fallas de rumbos oscilantes entre NE y NS.

Con respecto a la sismicidad y sismotectónica de esta zona, Güendel et al. (1992) reportan un mecanismo focal compuesto para un grupo de temblores que se ubicó en las cercanías del poblado de Orotina. Este tiene solución de fallamiento inverso con una componente transcurrente. De acuerdo con mi estudio neotectónico, la secuencia de Orotina ocurrió en la zona de intersección entre la falla Tárcoles y el sistema de falla Bijagual (Fig. 4). Por otro lado, en la figura 3 se puede observar que existe una buena cantidad de temblores de profundidad menor a $20 \mathrm{~km}$, que se localizaron cerca o sobre la traza de la falla Tárcoles. Es especialmente conspicuo en el lado marino, un alineamiento de temblores a lo largo de una traza de la falla Tárcoles que tiene rumbo NE. Asimismo, se muestran varios temblores del lado occidental de la traza marina de la falla Tárcoles, donde esta tiene rumbo NS. En Montero et al. (en preparación) se estudian con más detalle estos eventos, pero es muy posible que varios de estos se puedan asociar a esta falla, aunque otros se relacionan con la zona interplaca.

Existen una buena cantidad de evidencias acerca de la actividad reciente de esta falla. Entre estas mencionamos, la presencia de una zona de subsidencia reciente del lado occidental de la fa1la (Fischer, 1980), desplazamientos en depósitos aluvionales recientes, presencia de lomos de presión en depósitos recientes, desvío de drenajes, escarpes y contraescarpes facetados poco disectados, cambios de tonalidad de la vegetación, desvío de divisorias, sillas de falla, cambios de pendiente, entre otros.

\section{Subsistema de lineamientos Quebradas, Escobal, Guácimos y Tornos}

Más al este, dentro de los Montes del Aguacate, la falla Tárcoles parece subdividirse en una serie de lineamientos sugestivos de ser fallas recientes de poca longitud, que sugieren tener una componente normal con el bloque occidental descendiendo. Estos son:

\section{Lineamiento Quebradas ( $L Q)$}

Tiene rumbo NE y muestra alineaciones geomórficas prominentes en el sector noreste y expresión geomórfica moderada a débil en el extremo suroeste. Al noreste del poblado de Quebradas, se caracteriza por la presencia de valles lineales, lomas facetadas, sillas de falla y contraescarpes, que sugieren una posible componente de levantamiento local en el bloque oriental. En la margen sur del Río Grande de Tárcoles, podría unirse con un ramal de la falla Tárcoles que pasa cerca de Bolsón. 
Lineamiento Escobal (LE)

Lineamiento de rumbo NE, que en el sector noreste presenta alineaciones geomórficas prominentes, mientras que en el suroeste, tiene expresión geomórfica moderada a débil. Al noreste del poblado de Escobal, se caracteriza por mostrar ruptura de pendientes, angostamiento de divisoria, valles lineales, silla de falla y posible divisoria desplazada en sentido sinestral.

\section{Lineamiento Guácimos $(L G)$}

Lineamiento de rumbo NE, que al noroeste de Guácimos tiene una expresión geomórfica prominente. Muestra valles lineales alineados, silla de falla, posible divisoria desplazada en sentido sinestral.

\section{Lineamiento Tornos (LT)}

Lineamiento de rumbo NE, que en sus sectores central y noreste tiene una expresión geomórfica fuerte, mientras que en su extremo suroeste es de prominencia débil. Presenta valles lineales alineados, sillas de falla y contraescarpes facetados que miran al noroeste en su sector central, lo cual sugiere una componente de levantamiento en el bloque oriental.

\section{Falla La Garita}

Tiene rumbo NE y una prominencia moderada a débil. En el cañón del Río Grande, tiene un trazo de valle lineal y presenta una zona de falla ancha, dentro de la cual ocurren desplazamientos sinestrales predominantes con desplazamientos normales e inversos subsidiarios. Esta falla aparece en Arias y Denyer (1991) y Montero (1994b). Protti (1997) sugirió desplazamientos asísmicos en esta falla luego del terremoto de Cóbano de 1990.

\section{Sistema de fallas de Bijagual}

El sistema de fallas de Bijagual (SFB) tiene un rumbo que varía entre NS y NE (Fig. 2). Presenta tres fallas principales las cuales al norte, se unen con la falla Tárcoles, formando el límite este de la cuenca de tracción asociada al fallamiento sinestral, que se localiza entre el sector marino de la entrada del Golfo de Nicoya y el sector continental del antearco. En el continente, las fallas de rumbo $\mathrm{N}$ constituyen un sistema entrelazado de fallas de desplazamiento oblicuo sinestral-normal. En el sector comprendido entre playa Herradura y Esterillos, varias trazas de este sistema de fallas tienen rumbo NE. Los datos de Fischer (1980), sugieren que varias de estas trazas coinciden con zonas de levantamiento o hundimiento diferencial de terrazas bioerosionales. También, corresponde con una de las fallas que Fisher et al. (1998) ubican entrando por el Río Surtubal. Más al este, en la zona de Bijagual, estas trazas tienen un rumbo predominante NS y tienen escarpes que miran al este y localmente pueden definir zonas de tracción, como es la que se ubica cerca de Surtubal y la que esta al pie de la Fila Tronco Negro. La geometría de estas cuencas de tracción embrionarias indican que las fallas principales que las limitan tienen una componente sinestral. El sistema de fallas de Bijagual se localiza del lado oeste del cerro Turrubares. Cortan una antigua superficie estructural que se localiza a una altura entre 450 y 600 metros donde se ubica el poblado de Bijagual.

Con relación a la sismicidad y sismotectónica de estas fallas, tenemos que Güendel et al. (1993) reportaron un enjambre de temblores ocurrido entre el 21 y el 24 de enero de 1989, con profundidades entre 5 y $10 \mathrm{~km}$ al oeste de Orotina. El mecanismo focal compuesto realizado por estos autores, muestra una solución de desplazamiento oblicuo normal-sinestral (plano de rumbo

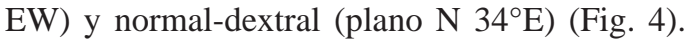
Según mi investigación neotectónica, estos temblores ocurrieron ligeramente al norte del extremo norte del sistema de fallas de Bijagual, en una zona donde no se ha identificado una expresión neotectónica para esta falla. Esto podría indicar un amortiguamiento del desplazamiento de esta 
falla en esta zona. Por otro lado, Fernández (1995) reporta un mecanismo focal de tipo transcurrente con componente normal, en la zona donde se ubica el sistema de fallas de Bijagual. Sin embargo, los planos nodales son de rumbo NE y NW. Asimismo, en la figura 3 se muestra una importante concentración de sismos a lo largo del sistema de fallas Bijagual. Algunos de estos temblores deben estar asociados con estas fallas, especialmente los que se localizaron del lado continental. Otros se relacionan con la subducción, pero su estudio detallado se presenta en Montero et al. (en preparación).

\section{Falla Tulín}

La falla Tulín (FT) fue definida por Arias \& Denyer (1991), como una falla de desplazamiento de rumbo sinestral con una componente de levantamiento en el lado noroeste. Posteriormente, Montero (1994a) le asocia un relevo distensivo en su extremo este, cerca de su intersección con la falla Candelaria, que concuerda con la geometría de falla sinestral. Se evidencia por su valle de falla prominente, que limita el sector sureste del cerro Turrubares. Al oeste, esta falla termina contra el sistema de fallas NS de Bijagual, mientras que al este la falla Tulín es cortada por la falla Candelaria. En la figura 3 esta falla se mostró pasiva sísmicamente para el período marzo de 1996 a enero de 1998.

\section{Falla Candelaria}

Dentro del sistema de fallas NW del sector occidental central del país, la falla Candelaria (FC) es la más relevante. Tiene una traza prominente hacia el sureste de su intersección con la falla Tulín. Hacia el noroeste la traza es débil y solo se observa un cambio de pendiente entre el cerro Turrubares y la zona oriental. En el sector donde la traza es prominente, la falla se alinea con el río Cajón y el río Grande de Candelaria, y muestra varios valles lineales alineados, sillas de falla, trincheras de falla, entre otros. Arias \& Denyer (1991) y Montero (1994a) sugieren un movimiento dextral para esta falla.
Al sureste del río Pirrís, la falla parece tener el bloque este levantado, tal como lo sugiere un escarpe que mira al suroeste, lo cual sugiere una componente inversa en la falla. Al cruzar la falla Candelaria al río Parrita, las dos trazas que presenta estan originando el desvío del río hacia el NW por causa de la presencia de espolones rocosos asociados a las filas Bijagua y Carbones, ambos ubicados del lado oeste de ambas trazas, lo cual sugiere una componente dextral de la falla en este sector.

\section{Actividad sísmica de Costa Rica anterior al terremoto de 1924}

La actividad sísmica de Costa Rica ocurrida entre 1900 y 1923, se caracterizó por varios terremotos en el margen pacífico, algunos de ellos ubicados en la zona aledaña a la zona epicentral del terremoto de 1924 (Fig. 1). Destacamos los eventos de tipo interplaca de Nicoya del 21 de junio de 1900 (Magnitud Milne, MM = 7,2), el de Osa del 20 de diciembre de 1904 (Ms = 7,5), el de la entrada del Golfo de Nicoya del 20 de enero de 1905 (Ms = 6,5), el de Bahía Culebra del 27 de febrero de 1916 (Ms = 7,3), del 24 de abril de 1916 $(\mathrm{Ms}=7,4)$, del Cinturón Deformado del Norte de Panamá del 26 de abril de 1916 (Ms = 6,9). También, ocurrieron varios temblores con magnitudes Ms entre 5,0 y 6,5, relacionados con el fallamiento cortical del arco interno de Costa Rica, como fueron el terremoto del Tablazo del 13 de abril de 1910 (Ms = 5,6), el terremoto de Cartago de 1910 (Ms = 6,1), el terremoto de Toro Amarillo del 28 de agosto de 1911 (Ms = 5,8), el sismo de Guatuso del 10 de octubre de 1911 (Ms = 6,5), el temblor de Tres Ríos del 21 de febrero de 1912 y el temblor de Sarchí del 6 de junio de 1912(Ms = $5,1)$. Como se observa, la actividad sísmica anterior al sismo de 1924 fue sumamente intensa con 
varios terremotos interplaca de magnitudes $\mathrm{M} \geq 6,75$ y otro buen número de temblores de magnitudes entre 5,0 y 6,5 relacionados al fallamiento cortical, la mayoría de ellos localizados hacia el este de la zona epicentral del terremoto de 1924. Se puede presumir que los esfuerzos inducidos por estos terremotos, bien pudieron sobrecargar de esfuerzos y temporalmente adelantar el terremoto de 1924.

Temblores de posible caracter cortical ocurridos en la zona focal del sismo de 1924, parecen haber sido observados unos cinco años antes. En el Diario de Costa Rica del 13 de marzo de 1924, se reproduce una entrevista con el Prof. Tristán, quien indica que "aquellos sismos locales que se sintieron en Orotina hace unos cinco años fueron el principio del desquiciamiento terrestre que ha culminado con los violentos temblores ocurridos en este mes de marzo”. Debemos indicar que en los diversos catálogos de temblores de Costa Rica, no hay reporte de ningún temblor de magnitud $\geq 6,0$ en 1919 .

Una nueva secuencia de temblores ocurrió a principios de 1923, dentro de la zona hipocentral de 1924. En el Diario de Costa Rica se reproduce el 7 de marzo de 1924 una nota que se publicó el 4 de enero de 1923 y que dice "Ayer conversamos con un afincado de Turrubares, que nos informó de una serie de fenómenos sísmicos que tienen alarmados a los vecinos... El jueves pasado la cosa pasó de punto pues se registró un temblor tan fuerte como los de abril de 1910. Los temblores son locales pues ya en Coyolar apenas se sienten débiles. Se oyen ruídos subterráneos y se han derrumbado varias peñas... El vecindario esta alarmado y se sospecha del nacimiento de un nuevo volcán en Herradura o Turrubares...". Aquí, nuevamente indicamos que en los diversos catálogos de temblores de Costa Rica, no hay reporte de ningún temblor de magnitud $\geq 6,0$ en 1923 o a fines de 1922.

¿Que ocurrió sísmicamente en los meses anteriores a 1924?. Según el conteo diario de los temblores que realizó el Observatorio Nacional, ubicado en San José, durante los dos meses anteriores al terremoto de 1924, hubo un ligero incremento de la actividad sísmica de enero a febrero, debido a un enjambre de temblores que ocurrió entre el 7 y el 12 de febrero. En el mes de enero se detectaron 41 temblores, donde el de mayor intensidad tuvo entre II y III grados. En el mes de febrero se contaron 62 temblores, el mayor de los cuales ocurrió el 13 de febrero y tuvo intensidad III (Fig. 5). Sin embargo, no se conocen las zonas sísmicas donde se originaron los anteriores eventos.

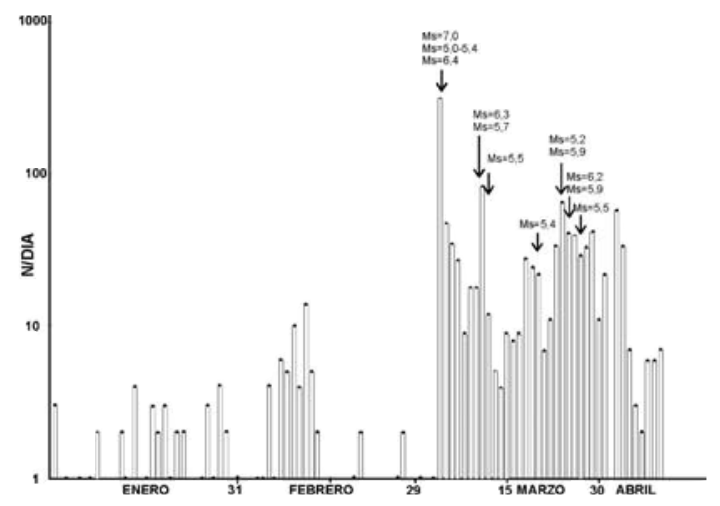

Fig. 5: Sismicidad de los dos meses anteriores y un mes posterior al terremoto de 4 de marzo de 1924, según datos del Observatorio Nacional. Se observa un enjambre de temblores ocurrido alrededor del 10 de febrero. El nivel de actividad sísmica era bajo unos dias antes del sismo del 4 marzo de 1924. Luego del evento principal se observa el decaimiento hiperbólico de las actividad sísmica, pero con picos de actividad superpuestos, que aumentan el número de eventos por día luego de la ocurrencia de réplicas con magnitudes $\mathrm{Ms} \geq 5,0$.

\section{¿Ocurrió un evento precursor?}

De acuerdo con las localizaciones hipocentrales efectuadas por el International Seismological Summary (ISS) y por Ambraseys (1995), durante la secuencia sísmica que ocurrió en la región pacífica central de Costa Rica en 1924 (cuadro 1), se reporta un evento precursor a las 02 h 06 min del 4 de marzo de 1924, el cual ocurrió prácticamente 8 horas antes del sismo principal. De acuerdo con Ambraseys (1995), este tuvo una magnitud Ms = 5,2. Sin embargo, en el recuento de los sismos diarios de ese mes realizado por el Observatorio Nacional, el sismo anterior al terremoto principal ocurrió a las $16 \mathrm{~h}$ 56 min, hora local (22:56 GMT) del día 3 de marzo. Por lo tanto, este reporte no incluye 
ningún temblor ocurrido en la hora indicada por el ISS, lo cual es sumamente extraño considerando especialmente la magnitud $\mathrm{Ms}=5,2$ que tuvo el supuesto evento precursor. Adicionalmente, en los reportes recopilados en los periódicos y de las entrevistas efectuadas en la zona afectada, no se menciona nada sobre la ocurrencia de un sismo precursor. Para aclarar este punto hemos revisado nuevamente el boletin del ISS y hemos deducido las diferencias de tiempo S-P, en las diferentes componentes de la estación más cercana a la secuencia de 1924, que era la estación de Balboa, Panamá (BHP). Encontramos que los S-P leídos para el supuesto evento precursor fueron de 36 y $40 \mathrm{~s}$, lo que equivale a alrededor de $390 \mathrm{~km}$ de distancia epicentral de BHP. Esto corresponde con un círculo con un radio que pasaría por la zona fronteriza de Costa
Rica-Panamá (Fig. 6). Por lo tanto, este S-P es bastante más corto que el que se estima para la secuencia de 1924, que debió ser de alrededor de $54 \mathrm{~s}$, como fue el S-P leído para el evento principal (entre 52 y $64 \mathrm{~s}$ ). Incluso, los S-P de las réplicas son en general bastante mayores que el S-P del supuesto evento precursor, los cuales oscilan entre 60 y $80 \mathrm{~s}$ para los sismos ocurridos entre el día 4 y el día 24, hasta las 11 h 40 min. La réplica del día 24 de las 20 h 29 min tiene un S-P entre 44 y 48 s y las de los días 25 al 28 de marzo oscilan entre 46 y $66 \mathrm{~s}$. Lo anterior nos lleva a concluir que el sismo de las $02 \mathrm{~h} 06 \mathrm{~min}$ del 4 de marzo no fue un evento precursor, ocurriendo en una zona sísmica diferente de la de 1924 y tuvo su epicentro posiblemente alejado de San José y de la zona de Orotina, porque no fue reportado sentido en estos lugares.

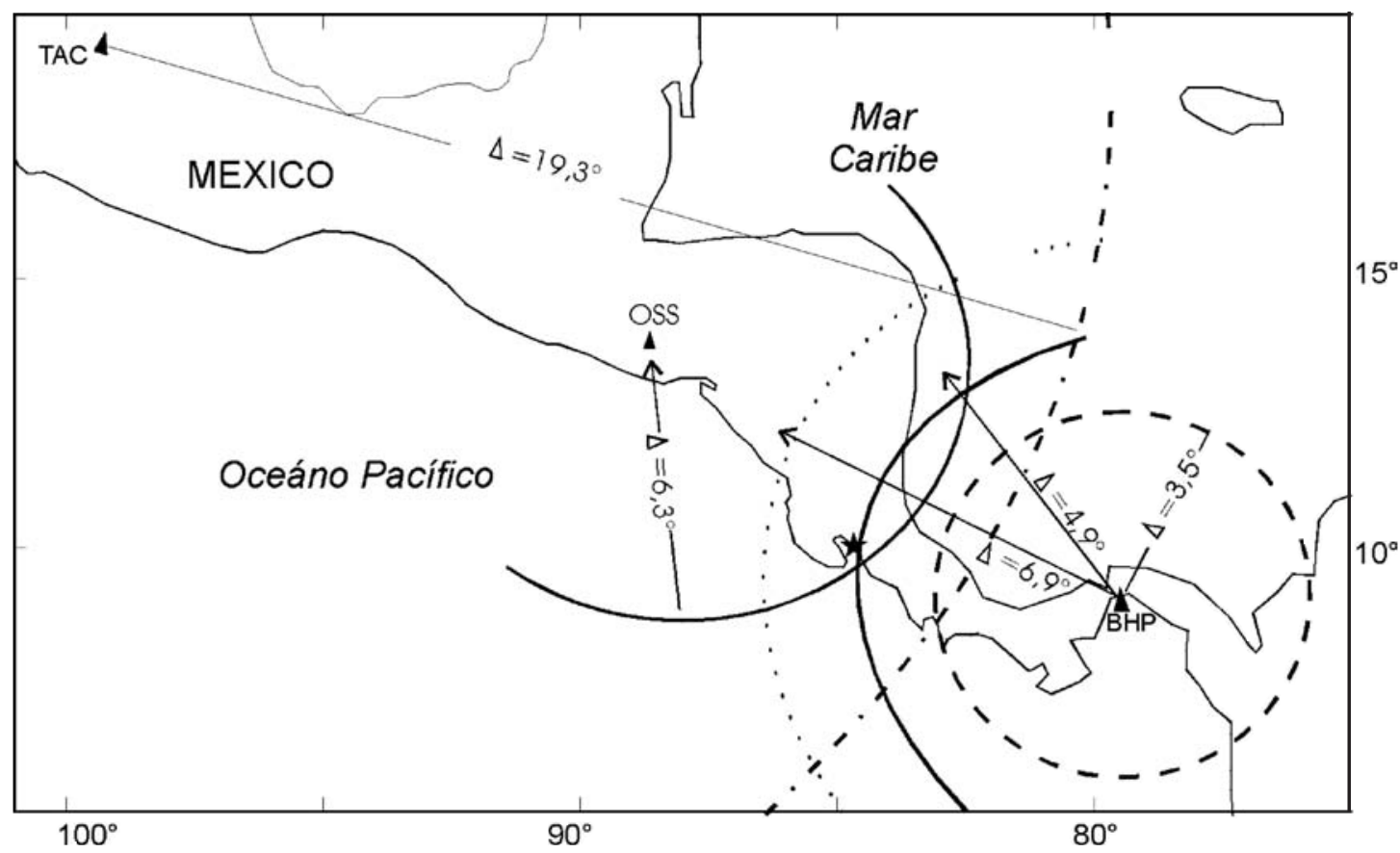

Fig. 6: Ubicación de las estaciones sismológicas TAC en México D. F., el Observatorio Sismológico de El Salvador (OSS) y BHP, en la Zona del Canal de Panamá. Para cada estación se dibujan los círculos con un radio igual a la distancia en grados, deducida del S-P, considerando un foco superficial (TAC y BHP) o la distancia epicentral reportada (OSS). Para BHP, el círculo con un radio de $3,5^{\circ}$ del supuesto evento precursor, pasa por la zona fronteriza de Costa Rica-Panamá (a trazos). Además, el círculo de $4,9^{\circ}$ equivale al S-P del evento principal (trazo continuo fuerte). El de radio de $6,9^{\circ}$ es para las réplicas con el mayor S-P reportado (círculo punteado). Los círculos para el evento principal de OSS y BHP se cortan cerca de Herradura, practicamente en el sitio escogido para el epicentro del terremoto de 1924 (estrella rellena). 


\section{CUADRO 1}

SECUENCIA SISMICA ASOCIADA CON EL TERREMOTO

DEL 4 DE MARZO DE 1924 (10 h: $07 \mathrm{~min})$

\begin{tabular}{|c|c|c|c|c|c|}
\hline $\mathrm{N}$ & $\begin{array}{l}\text { Fecha } \\
\text { Día h Min s }\end{array}$ & Epicentro* & $\mathrm{h}$ & Ms** & Comentario \\
\hline 1 & 04020612 & $9,70^{\circ} 85,00^{\circ}$ & $\mathrm{n}$ & 5,2 & Precursor? \\
\hline \multirow[t]{2}{*}{2} & 04100742 & $9,80^{\circ} 84,70^{\circ}$ & $\mathrm{n}$ & 7,0 & Evento principal. \\
\hline & & $9,83^{\circ} 84,58^{\circ}$ & 15 & $6,6 \mathrm{mb}$ & I= VII en San José. \\
\hline 3 & 041049 & $9,83^{\circ} 84,58^{\circ}$ & 15 & $(5,0-5,5)$ & I= VIII RF en San José \\
\hline 4 & 04114336 & $9,80^{\circ} 84,70^{\circ}$ & $\mathrm{n}(15)$ & 6,4 & $\begin{array}{l}\text { Réplica principal. } \\
\text { I = V RF en San José. }\end{array}$ \\
\hline 5 & 11104108 & $9,90^{\circ} 84,60^{\circ}$ & $\mathrm{n}(15)$ & 6,3 & I = VI RF en San José. \\
\hline 6 & 11203406 & $9,80^{\circ} 84,50^{\circ}$ & $\mathrm{n}(15)$ & 5,7 & I = IV RF en San José \\
\hline 7 & 12025020 & $9,80^{\circ} 84,50^{\circ}$ & $(15)$ & 5,5 & \\
\hline 8 & 20095612 & $9,80^{\circ} 84,50^{\circ}$ & $\mathrm{n}(15)$ & 5,4 & $\mathrm{I}=\mathrm{V}$ RF en San José \\
\hline 9 & 24114015 & $9,80^{\circ} 84,50^{\circ}$ & $\mathrm{n}(15)$ & 5,2 & I = IV RF en San José. \\
\hline 10 & 24202900 & $9,80^{\circ} 84,50^{\circ}$ & $\mathrm{n}(15)$ & 5,9 & I = VI RF en San José \\
\hline 11 & 25140700 & $9,60^{\circ} 84,30^{\circ}$ & $\mathrm{n}(15)$ & 6,2 & I= VI RF en San José \\
\hline 12 & 25150332 & $9,60^{\circ} 84,30^{\circ}$ & $\mathrm{n}(15)$ & 5,9 & $\mathrm{I}=\mathrm{V}$ a VI RF en San José \\
\hline 13 & 27082945 & $9,80^{\circ} 84,20^{\circ}$ & $\mathrm{n}(15)$ & 5,5 & I = V RF en San José. \\
\hline 14 & 28045700 & $9,80^{\circ} 84,20^{\circ}$ & $\mathrm{n}(15)$ & 4,8 & \\
\hline
\end{tabular}

Notas:

* $\quad$ En esta y la siguiente columna se indican la localización epicentral y la profundidad reportada por Ambraseys (1995) donde $\mathrm{n}$ indica profundidad < 40-60 km. Entre paréntesis las profundidades estimadas en este estudio. El epicentro y la profundidad estimados en este trabajo para el evento principal se ubican en el siguiente renglón.

** Indica magnitud Ms según Ambraseys (1995). También se proporciona la magnitud mb determinada por Ambraseys (1995) para el evento principal. Entre paréntesis se indica la magnitud Ms estimada en este estudio para la réplica de las 10:49 (GMT) del 4 de marzo. En comentario las intensidades Rossi-Forel (RF) son del Observatorio Nacional.

\section{Distribución temporal, espacial y de magnitudes del evento principal y de las principales réplicas según el ISS y Ambraseys (1995)}

El terremoto del 4 de marzo ocurrió a las $10 \mathrm{~h} 07 \mathrm{~min}$ (GMT) y fue localizado por ISS, con epicentro en $9,5^{\circ} \mathrm{N}$ y $84,0^{\circ} \mathrm{W}$. Las réplicas de mayor magnitud, fueron también ubicadas con el mismo epicentro por el ISS. Este epicentro instrumental se ubica dentro de la zona donde la intensidad estimada fue de VI grados, al sureste del área de mayores intensidades (VIII-IX). Más recientemente, Ambraseys (1995) reubicó el temblor principal en las coordenadas $9,8^{\circ} \mathrm{N}$ y $84,7^{\circ}$ $\mathrm{W}$, así como varias de las principales réplicas (cuadro 1). La figura 2 muestra las localizaciones de este último autor, todas las cuales tuvieron foco de profundidad normal (h $<40-60 \mathrm{~km}$ ). Estas se basan parcialmente en datos macrosísmicos y son sustancialmente mejores que las del ISS, dado que se ubican dentro de la zona que fue más afectada por esta secuencia sísmica.

La magnitud asignada por Gutenberg \& Ritcher (1954) para el evento principal fue $\mathrm{M}=$ 7,0. Duda (1965), Abe (1981) y Ambraseys (1995), revisaron esta magnitud utilizando diferentes criterios, concordando con el valor originalmente asignado por Gutenberg \& Richter (1954). Aunque la secuencia de réplicas duró varios meses de acuerdo con los datos recopilados en periódicos y entrevistas personales, los eventos con magnitudes entre Ms 4,8 y 6,4, ocurrieron durante el mes de marzo.

La descripción que realiza el Observatorio Nacional del evento principal señala "Gran 
temblor que vino súbitamente. El sismógrafo Ewing no funcionó, pero la duración completa del sismo se ha apreciado en dos minutos y 30 segundos, incluyendo el tremor que fue cortísimo. La fase principal de dirección NNW a SSE y que duró aproximadamente 50 segundos, tuvo por lo menos cinco remezones violentos, los que produjeron los primeros daños, como caída de repellos, ladrillos, etc. La fase final se caracterizó por una serie de balanceos de gran amplitud con la circunstancia, muy especial, de que estos balanceos cambiaron de dirección del $W$ al E..”. En esta descripción destaca un tremor cortísimo, el cual relacionamos con una fase $\mathrm{P}$ de poca duración, sugiriendo un S-P corto. Además, se indica que la fase principal fue de dirección NNW a SSE. Interpretamos que esta corresponde con la fase $S$, por lo que el epicentro debió estar al WSW de San José. Más adelante, utilizamos este dato y otros más, para localizar el terremoto del 4 de marzo y tener una mejor idea del área de réplicas.

Una restricción adicional de la orientación de los epicentros con relación a San José, lo

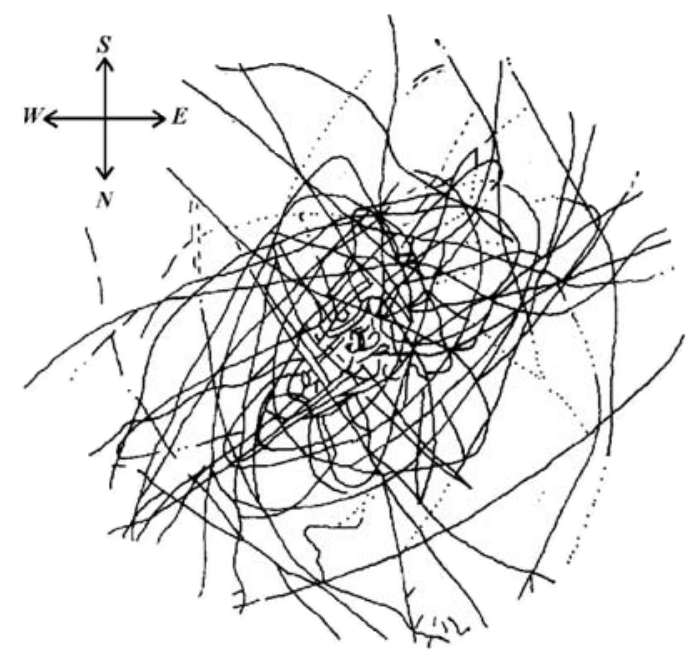

Péndulo Trifilar

Fig. 7: Registro del sismoscopio ubicado en el Observatorio Nacional para el terremoto del 4 de marzo de 1924 (Diario de Costa Rica, 6 de abril de 1924). Se observan las fuertes oscilaciones NE y NW, que presumiblemente corresponden a las fases $\mathrm{P}$ y $\mathrm{S}$ respectivamente. constituye un registro del evento principal inscrito por el sismoscopio del Observatorio Nacional. Una reproducción de este se encuentra en el Diario de Costa Rica, página 4, del 6 de abril de 1924 (Fig. 7). Se pueden observar dos direcciones principales de movimiento del péndulo "trifilar", con respecto al registrador ahumado, aunque el movimiento de la partícula del suelo fue bastante complicado. Estas son: NW a SE y NE a SW. Otra dirección menos importante fue la NS. Las oscilaciones de dirección NW a SE parecen ser las de mayor amplitud, dado que van de un borde al otro del disco registrador y se interpreta que corresponden con la fase sísmica S. Las oscilaciones de dirección NE a SW corresponderían con la fase $\mathrm{P}$. El anterior análisis sugiere que el epicentro se ubicó al SW de San José.

Sin embargo, consideramos que el reporte de dirección emanado directamente del Observatorio Nacional es más preciso que nuestra sugerencia de que el evento se ubicó al SW de San José, dado que corresponde con un reporte oficial usando los datos originales. Por lo tanto, estimamos que el terremoto del 4 de marzo se ubicó al WSW de San José (azimut entre $240^{\circ}$ y $265^{\circ}$ ).

\section{El enigma de la réplica de las $10 \mathrm{~h} 49 \mathrm{~min}$ (GMT) del 4 de marzo}

Según el reporte del Observatorio Nacional, a las $4 \mathrm{~h}$ y $49 \mathrm{~min}$ (hora local) hubo un sismo de intensidad VIII en San José, que fue referido así:

"Segundo gran temblor de duración total aproximada de 1 minuto y 15 segundos; con caracter susultorio. Tremor bastante corto de $8 \mathrm{se-}$ gundos. En la fase principal hubo un balanceo muy fuerte acompañado de una serie de vibraciones trepidatorias violentas que produjeron daños materiales de bastante consideración. La duración del balanceo de la fase final, fue muy corta, aproximadamente de 25 segundos..."

En la anterior descripción aclaramos que desconocemos el significado de la palabra susultorio; probablemente es un localismo usado para describir el tipo de movimiento del temblor. Vemos que este fue un sismo sumamente fuerte y largo en San José, al que se le asignó una 
intensidad bastante alta (VIII), que causó daños importantes en la ciudad capital. Sobre este temblor hablan diversos testigos de la secuencia sísmica de 1924, quienes destacan que causó daños en la región occidental del Valle Central y en el Pacífico Central. En Atenas fue reportado con especial intensidad (Wilfredo Rojas, comunicación verbal, 1998).

Lo interesante de esta réplica es que a pesar de su alta intensidad, la misma no fue localizada por el ISS ni por Ambraseys (1995). Tampoco, existe estimación de magnitud para la misma. Para tratar de entender la causa de esta circunstancia, hemos revisado nuevamente el boletín del ISS y hemos encontrado la indicación de que para el 4 de marzo existen lecturas adicionales ( $\sin$ indicarse el tipo de fase) para un sismo (?) a las $10 \mathrm{~h}$ en las estaciones de Tacubaya (TAC, México D.F.), Balboa (BHP) y La Paz, Bolivia. Además, se hace la acotación interesante de que la lectura en BHP es para un sismo cercano a esa estación, lo cual nos lleva a suponer que se trate del evento de las 10 h 49 min.
Hemos obtenido copia del sismograma del terremoto de 1924 para la estación de TAC, ubicada en México D. F. ( Fig. 8). En el mismo no ubicamos esta réplica; no encontramos una fase de $\mathrm{P}$ que se pueda identificar, como si ocurre con la réplica de las $11 \mathrm{~h} 43 \mathrm{~min}$, que tuvo magnitud Ms $=6,4$. Por otro lado, en el boletín del ISS, TAC reportó todas las réplicas mayores a Ms 5,5. Por lo anterior, este sismo parece haber tenido una magnitud entre 5,0 y 5,5 Ms. Otra posibilidad, es que el temblor de las 10 h 49 min haya quedado enmascarado dentro del tren de ondas registrado en la parte final del terremoto principal que registró TAC y que por lo tanto, su magnitud pudo ser mayor que la sugerida.

Con respecto a la localización de esta réplica, destaca en el reporte del Observatorio Nacional, que el tremor duró 8 segundos. Obsérvese que aún en este año trabajaba el sismógrafo Ewing, del cual se habían obtenido sismogramas de terremotos como el de Guatuso del 10 de octubre de 1911(Tristán, 1911). Nuestra interpretación es que la duración del tremor indica la duración

\section{a) Evento Principal (10:07 GMT, Ms=7,0)}

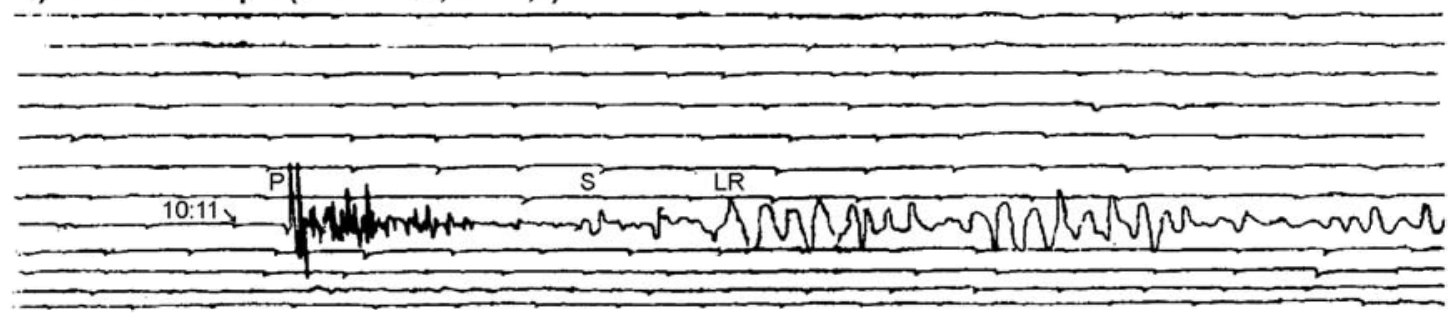

b) Réplica Principal $(11: 43 \mathrm{GMT}, \mathrm{Ms}=6,4)$

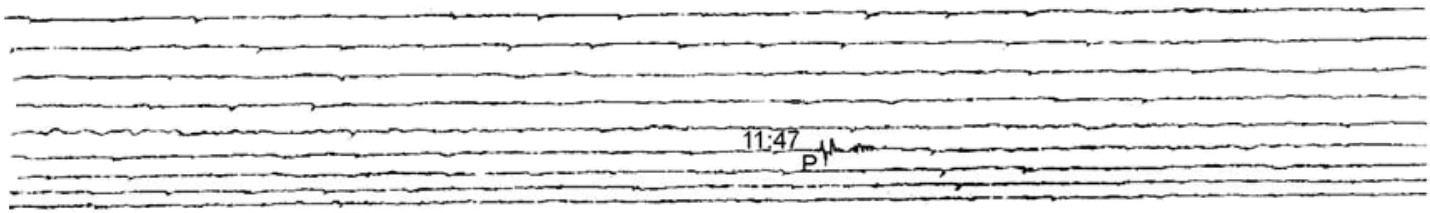

Fig. 8: Reproducción del sismograma de la Estación Tacubaya (TAC) ubicada en México D. F., México, para el terremoto del 4 de marzo de 1924 (parte superior de la figura) y para la réplica mayor (parte inferior de la figura). No se observa la réplica de las 10: 49 GMT, que debe ubicarse en la traza superior a la réplica de las 11:43 GMT. P, S y LR señalan la entrada de las ondas P, S y Rayleigh. 
de inscripción de la fase P. Por lo tanto, el S-P de este evento debió ser de 8 segundos. Si consideramos que el sismo fue superficial y que la razón de velocidades $\mathrm{Vp} / \mathrm{Vs}$ es 3, una velocidad promedio de $\mathrm{Vp}$ de $5,85 \mathrm{~km} / \mathrm{s}$, entonces un S-P de 8 segundos equivale a una distancia epicentral de aproximadamente 64 km de San José, con un epicentro al oeste o suroeste de Orotina. Asignamos a este evento el mismo epicentro del sismo principal, lo cual se determina más adelante.

\section{Distribución temporal y espacial de las réplicas según el Observatorio Nacional}

El Observatorio Nacional realizó un conteo de los diferentes temblores que fueron registrados diariamente durante el mes de marzo y meses sucesivos de 1924. Desafortunadamente, no se conoce el paradero del documento original donde se llevaba la recopilación del tiempo de ocurrencia de los temblores, su intensidad RossiForel, y las características de dirección y duración de fases de los sismos registrados en el sismógrafo Ewing. Sin embargo, en los periódicos esta información fue parcialmente publicada, y con esta se pueden obtener datos útiles sobre las réplicas. He recopilado del Diario de Costa Rica, la información del número de sismos por día registrados con intensidad mayor o igual a I (RF) en el Observatorio Nacional, desde el día 4 de marzo al 10 de abril. Esta información permite definir el decaimiento temporal de la actividad de réplicas durante un poco más de un mes (Fig. 5). Vemos que una vez ocurrido el evento principal a las 4:07 (H. L.), se contaron un total de 312 temblores durante ese día. A partir de la ocurrencia del evento principal la actividad de réplicas fue decayendo rápidamente hasta el día 10 de marzo cuando se contabilizaron 18 réplicas. El 11 de marzo la actividad sísmica nuevamente recrudeció, luego de que ocurrieron dos temblores de magnitudes Ms = 6,3 y Ms = 5,7 y otro más el 12 de marzo de Ms = 5,5. El día 11 de marzo se registraron 83 temblores, siendo el segundo día con más réplicas de toda la secuencia sísmica. Nuevamente, la actividad de réplicas comenzó a decaer hasta el 18 de marzo cuando se dió un nuevo incremento de la sismicidad, que perduró hasta el 4 de abril. A partir del 5 de abril y hasta el 10 de abril que se suspendió la recopilación de estos datos, la actividad de temblores se mantuvo con valores menores a 10 eventos por día, que seguían la tendencia normal de decaimiento de la actividad de réplicas.

Es claro que dentro de la tendencia de decaimiento hiperbólico de las réplicas asociada con las rupturas del 4 de marzo, de acuerdo con la ley de Omori, estan superpuestos en la curva, incrementos de la sismicidad debido al desarrollo de nuevas zonas de ruptura, además de la asociada al evento principal. Entre estas destacan las que se asociaron con los terremotos del 11 y 12 de marzo. También, las nuevas zonas de ruptura que ocurrieron entre el 20 de marzo y el 27 de marzo. Aunque esta más allá del alcance de este trabajo el análisis detallado de cada una de estas réplicas en cuanto a su zona epicentral, es claro que cada uno de estos eventos fue por si mismo un terremoto, con las que debieron asociarse nuevas secuencias de réplicas (Fig. 5).

Del análisis de las réplicas reportadas por el Observatorio Nacional y recopiladas en el Diario de Costa Rica, es posible definir la zona epicentral de estas usando el S-P y el azimut aproximado de su fuente. Veamos algunos ejemplos. Una réplica bien caracterizada por el Observatorio Nacional es la del 6 de marzo de las 18:58 de la cual se dice: "temblor susultorio de intensidad VI, duración de tremor 5 segundos; fase principal 8 segundos, reflejos de las ondas 13 segundos; dirección principal de Norte a Sur y NNW a SSE. Característica principal: choque trepidatorio inicial, 5 segundos de movimiento preliminar, fuerte remezón de norte a sur seguido de oscilación NNW a SSE. Tiene ocho oscilaciones principales en la componente norte a sur y ocho también en la este a oeste. Movimiento oscilatorio de alguna amplitud y bastante rápido y el movimiento trepidatorio de poca amplitud y algo rápido también". Como se observa hay una excelente descripción de la onda P (trepidatoria y con duración de 5 segundos) y de la onda $\mathrm{S}$ (oscilatoria y de 8 segundos de duración). El S-P indicaría un temblor ubicado a unos $40 \mathrm{~km}$ de San José entre el W y el WSW (debido a que la onda S tenía dirección NS a NNW a SSE). 
Otro evento réplica que se caracterizó bastante bien fue el de las 10:25 (H. L.) del 11 de marzo: "a las 10:25 temblor ondulatorio intensidad V, duración tremor 6 segundos; fase principal 19 segundos; fase final 17 segundos; duración total 52 segundos; reflejos de las ondas 50 segundos; dirección dominante de $N W$ a SE con cambios de $W$ a E. El sismógrafo Ewing dió un grafo bastante detallado...". Interpretamos que este evento tuvo un S-P de 6 segundos y por tanto se ubicó al SW a aproximadamente $48 \mathrm{~km}$ de San José.

Con respecto a las direcciones dominantes de las réplicas, tenemos múltiples ejemplos que señalan que estas se ubicaron entre el W y el SW de San José. Aparte de los dos casos anteriores que provinieron del WSW y del SW, tenemos un gran número de ejemplos que indican direcciones similares. Así, un temblor del 7 de marzo 00:58, (GMT) tuvo dirección predominante $\mathrm{N}$ a S y NNW a SSE. Para el temblor del 20 de marzo (09:56 GMT), la dirección dominante en el registro del sismógrafo Ewing fue NNW a SSE con movimientos combinados $\mathrm{N}$ a S y al finalizar $\mathrm{W}$ a E. Otro temblor fuerte ocurrido el 25 de marzo (14:06 GMT) tuvo dirección NW a SE y de W a E. El mismo día a las 15:09 (GMT) hubo un temblor con dirección marcada del NW a SE combinado con WSW a ENE. Los reportes anteriores

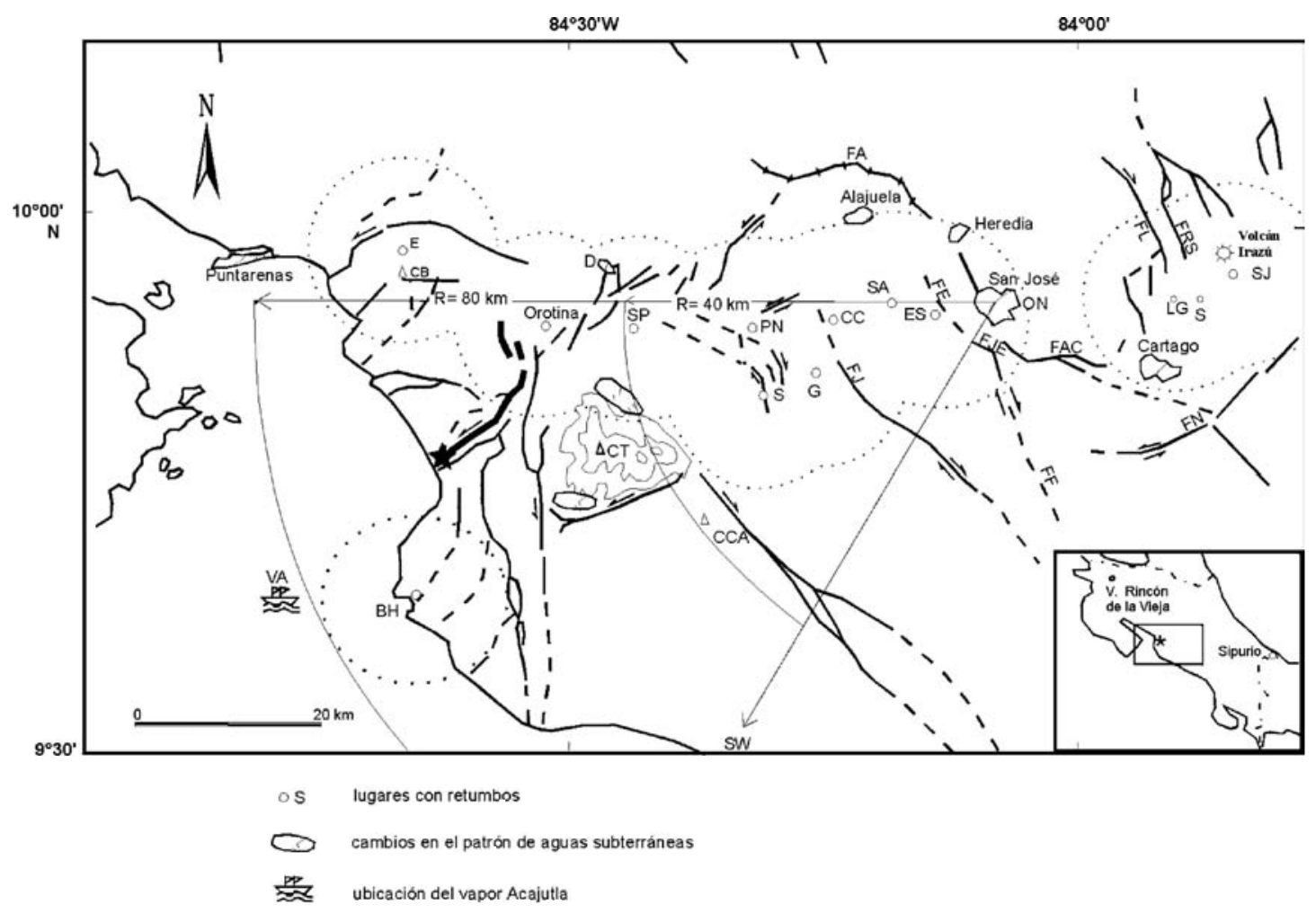

Fig. 9: Sistema de fallamiento de la región central pacífica de Costa Rica. FJ: falla Jaris, FE: falla Escazú, FJE: falla Jericó, FF: falla Frailes, FAC: falla Agua Caliente, FN: falla Navarro, FL: falla Lara, FRS: falla Río Sucio. Las otras fallas fueron referidas en la figura 2. Se ha dibujado círculos con un radio de $10 \mathrm{~km}$ alrededor de cada uno de los lugares donde se reportaron retumbos, para indicar las zonas con las fallas más probables donde se originaron estos temblores. Los lugares son E: Esparza, BH: Herradura, SP: San Pablo de Turrubares, PN: Piedras Negras, S: Santiago de Puriscal, G: Guayabo, CC: Ciudad Colón, SA: Santa Ana, Es: Escazú, LG: Llano Grande, S: Sanatorio Durán y SJ: San Juan. Con triángulos se muestra la ubicación de los cerros Bandera (CB), Turrubares (CT) y Cangreja (CCA). El cono con foco en el Observatorio Nacional (ON) en San José, cubre el intervalo de direcciones de donde provenían las réplicas. El área de réplicas se ubica entre los arcos concéntricos comprendidos entre la distancia mínima $(40 \mathrm{~km})$ y máxima $(80 \mathrm{~km})$ de estas, de acuerdo al S-P. 
indican una dirección predominante entre NS y NW a SE, con una mayor frecuencia de eventos con onda S de dirección NNW.

Mi interpretación indica un rumbo bastante similar de la fase $\mathrm{S}$, que implicaría áreas de ruptura para la secuencia de 1924, entre W y el SW con respecto a la ciudad de San José. Además, los S-P que han sido recopilados, nos permiten definir que las réplicas tuvieron entre 5 segundos como valor mínimo $(40 \mathrm{~km})$ y 10 segundos como valor máximo $(80 \mathrm{~km})$. La figura 9 muestra la zona azimutal que sugieren las direcciones de las réplicas y las distancias epicentrales mínima y máxima de las mismas.

\section{DISTRIBUCIÓN DE ISOSISTAS}

El terremoto del 4 de marzo de 1924 causó una enorme destrucción en la parte central pacífica del país. Las diversas réplicas contribuyeron a aumentar estos daños, aunque fueron especialmente dañinas la de las $10 \mathrm{~h}$ y $49 \min (5,1$ $<\mathrm{Ms}<5,5)$, y la de las $11 \mathrm{~h}$ y 43 m (GMT) de magnitud $\mathrm{Ms}=6,4$. Los reportes de daños y la forma como fueron percibidos estos temblores, aparecen profusamente detallados e ilustrados en los diversos periódicos de la época.

La figura 10 muestra la distribución de isosistas en Costa Rica hasta el grado de intensidad MM V. Los datos recopilados solo permiten dibujar parcialmente las isosistas de menor intensidad, dado que estos valores fueron observados en gran parte fuera del país. El temblor alcanzó a ser percibido a distancias tan lejanas como Balboa en Panamá y en Bocas, en el Departamento de Chontales, Ciudad Rama en Bluefields y en gran parte de la costa caribe y en la zona del gran lago en Nicaragua. El área de percepción del temblor no es fácil de estimar porque la isosista de intensidad II no cierra en tierra firme; la mayor parte de su configuración debe ser inferida en las áreas oceánicas. La distancia mayor donde fue percibido el temblor dentro del territorio de Panamá, fue en Balboa, a unos 530 km de la zona mesosísmica; en Nicaragua, este fue sentido en Boaco a $300 \mathrm{~km}$ de distancia de la zona más afectada. Una estimación grosera del área de percepción considerando un radio promedio de 420 $\mathrm{km}$, deducido de las máximas distancias epicentrales reportadas en Nicaragua y Panamá, daría un área de percepción de alrededor de 550000 $\mathrm{km}^{2}$. Gutenberg y Richter (1956) obtuvieron para California la relación:

$$
\mathrm{M}=-3,0+3,8 \log \mathrm{r}
$$

donde $\mathrm{r}$ es el radio medio de percepción y $\mathrm{M}$ la magnitud. Si consideramos $r=420 \mathrm{~km}, \mathrm{M}$ sería 7,0, lo cual concuerda con la magnitud M estimada instrumentalmente. Toppozada (1975) obtuvo para California y el oeste de Nevada:

$$
\mathrm{M}_{\mathrm{L}}=-1,88+1,53 * \log \mathrm{A}(\mathrm{I})
$$

donde $\mathrm{A}$ (I) es el área de percepción y $\mathrm{M}_{\mathrm{L}}$ es la magnitud local definida por Richter (1954). Sustituyendo A(I) por $550000 \mathrm{~km}^{2}$, obtenemos $\mathrm{M}_{\mathrm{L}}=6$,9. Los valores de magnitud obtenidos con base en el radio de percepción, son consistentes con los estimados mediante relaciones empíricas. El área de percepción está por tanto, de acuerdo con los valores esperados para un terremoto de magnitud Ms = 7,0.

$\mathrm{Al}$ área mesosísmica que incluye Orotina y San Mateo y la zona al sur-suroeste de estas poblaciones, se le asignó intensidad IX, luego de considerar los daños observados en diferentes poblados, los efectos sobre el terreno y la forma como fue percibido el temblor (Fig. 11). Un ejemplo de las observaciones macrosísmicas en este nivel de intensidad, fueron las recopiladas en Coyolar de Orotina: "una caja de caudales bastante pesada fue arrojada de la casa del señor Castro, también quedó volcada una cepilladora montada sobre barras de cemento y sujeta a esta por potentes pines de acero. Pequeñas casas de madera hundiéronse y otras cayeron de lado"; en Orotina "las casas se ladearon y están enterradas diagonalmente". En los periódicos aparecen algunas fotos que muestran casas de madera totalmente colapsadas, aunque otras aparentemente resistieron bien el temblor. En Orotina la cañería fue destruída quedándose la población 


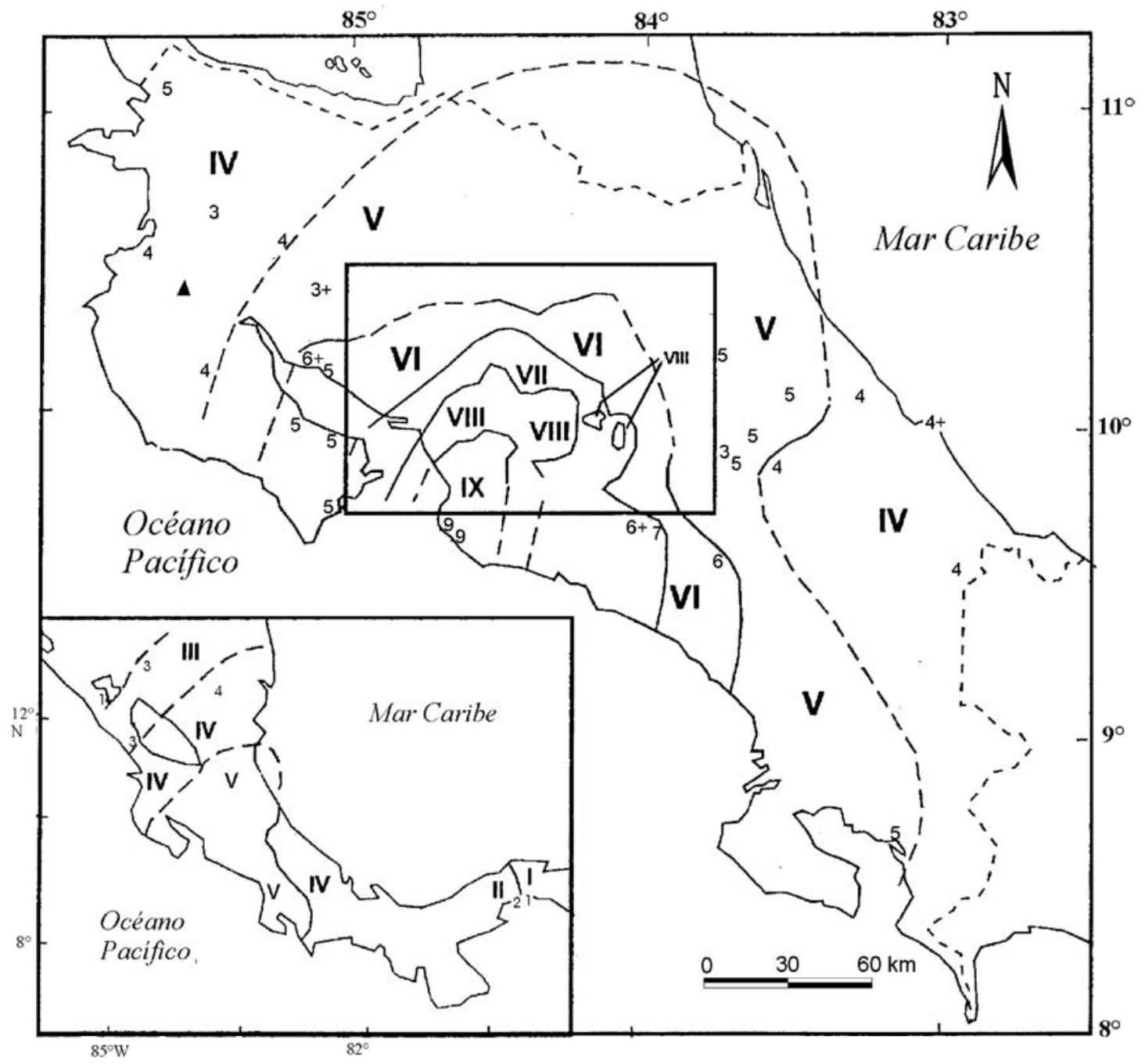

Fig. 10: Mapa de isosistas del terremoto del 4 de marzo de 1924. El número indica el nivel de intensidad observado en cada localidad. Se utiliza el + cuando la intensidad es incierta entre dos niveles de intensidad sucesivos. El triángulo indica un sitio en donde hay datos macrosísmicos pero no se asignó intensidad.

sin agua. En las faldas del Cerro Turrubares, el "Administrador de finca que queda en el Cerro informa, que durante el temblor fue lanzado de la cama contra un tabique. El edificio que ocupaba de dos pisos de madera quedó inutilizado no obstante, su magnífica construcción". En Capulín de Orotina: "los árboles fueron arrancados de cuajo, en una finca una maquinaria de hierro fue lanzada al aire”. En San Mateo, las fotos muestran la casa cural y la iglesia destruídas y los tubos de cañería rotos. En Tronco Negro de Turrubares: "las casas se levantaron como tres varas". Además de los daños en construcciones, se presentó dentro del área mesosísmica, gran cantidad de deslizamientos, caída de rocas, agrietamientos en el terreno y licuefacción. Esta última fue reportada en Herradura y Jacó y zonas aledañas. Una señora describe así la licuefacción en 
Jacó: "que de algunas grietas salen chorros considerables de agua sucia color ceniza y que el terreno a lo largo de la costa, que es de arena, pero que siempre ha sido dura, ahora esta completamente suave, hundiéndose a gran profundidad las personas o cualquier objeto que sobre el descanse..." (Diario de Costa Rica, 29 de marzo). Las anteriores son algunas de las observaciones macrosísmicas que nos llevaron a asignar intensidad IX en el área mesosísmica.

Deslizamientos, agrietamientos y caídas de roca fueron reportados en una extensa región que comprendió los Montes del Aguacate, especialmente entre el sur de San Ramón, San Mateo y Atenas, a lo largo del cañón del Río Grande de Tárcoles desde Balsa hasta su desembocadura; en el cerro Turrubares; en el Promontorio de Herradura y en las zonas de colinas y en los cañones de los ríos entre Esparza y Orotina y San Mateo. Incluso, en la zona de Toro Amarillo y en los alrededores de Zarcero, Puriscal y al sureste hasta en la zona de la cuesta de la Candelaria hacia San Marcos de Tarrazú, se describen los mismos fenómenos. Muchos de los deslizamientos cerraron temporalmente el cauce de los ríos, causando crecidas y la pérdida de ganado en fincas. Estas deformaciones del terreno se localizan en zonas entre intensidades IX a VII, y ayudan a la definición de la intensidad en dependencia de su frecuencia y magnitud.

Destacamos que las observaciones de daños ocurridos en las diversas obras de construcción no distinguen los que resultaron del temblor principal, de otros que fueron consecuencia del factor acumulativo de las cargas sísmicas debido a las réplicas, y muy especialmente a la de las 10 h y 49 min y a la de las 11 h y 13 min (GMT)(Ms $=6,4$ ), que ocurrieron dentro de la siguiente hora del evento principal. Por eso, las intensidades determinadas en las diferentes poblaciones, por lo menos hasta la intensidad VII, resultan de los daños acumulados y provocados tanto por el evento

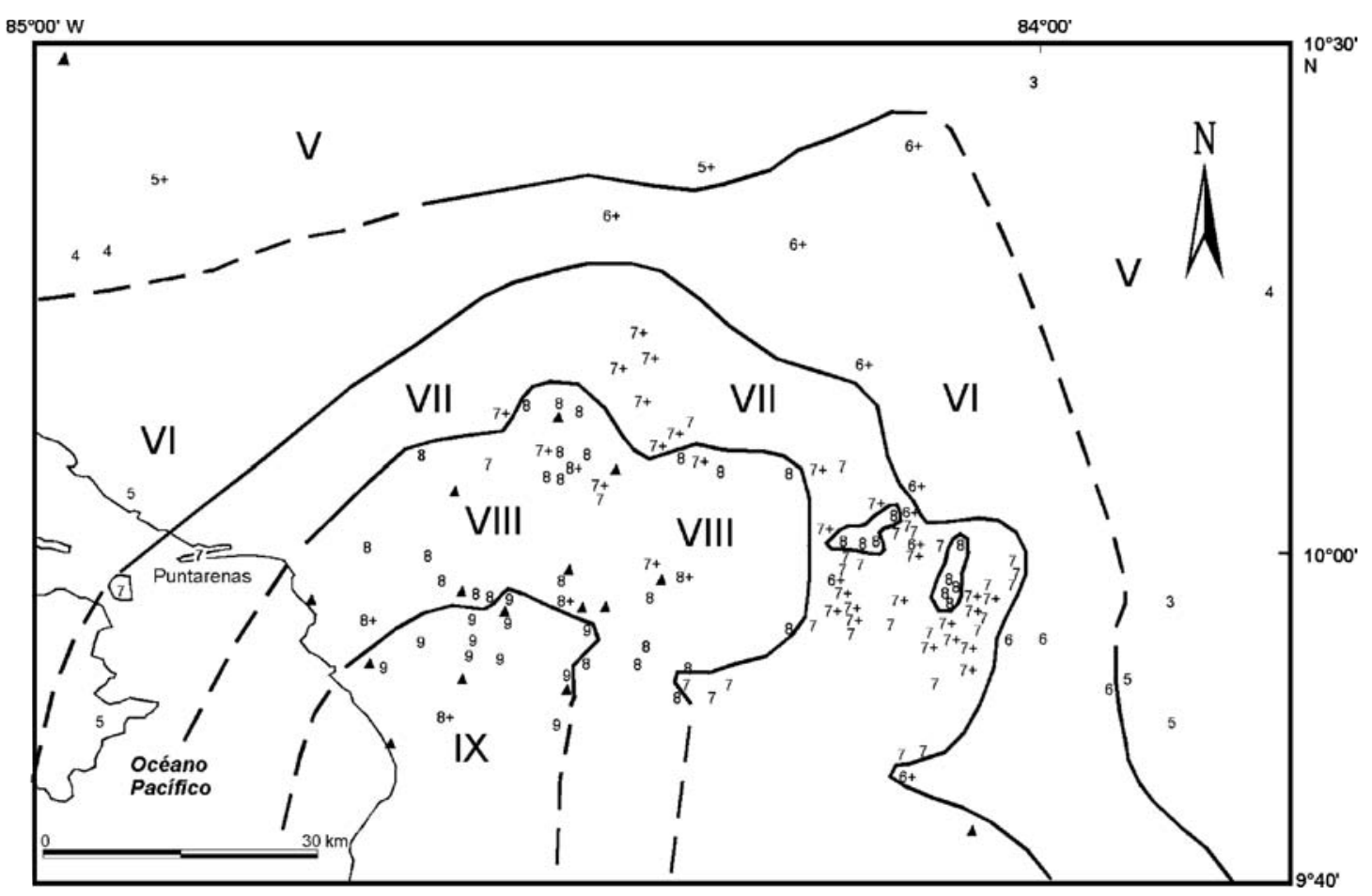

Fig. 11: Detalle de la distribución de intensidades en la región central pacífica de Costa Rica. A trazos cuando esta poco restringida. Misma simbología a la de la figura 10. 
principal como por las réplicas de mayor magnitud ocurridas el mismo día.

Las isosistas entre IX y VII grados muestran cierta elongación hacia el nor-noreste (Figs. 9 y 10). Sin embargo, también hay una marcada elongación hacia el este, evidenciando un menor decaimiento de las intensidades a lo largo del Valle Central Occidental. Esto se explica porque esta región esta en gran parte cubierta por suelos laháricos, piroclásticos y aluvionales que en algunos sectores alcanzan un espesor importante. Es decir, en el Valle Central Occidental, la isosista de intensidad VII muestra una configuración que sigue groseramente el contacto entre el suelo suave y el duro, sugiriendo por consiguiente un control geológico en la distribución de las intensidades entre VII y VIII grados. Las intensidades VII asignadas a la mayoría de las poblaciones del sector oeste del Valle Central, incluyen reportes de daños en diversas construcciones, aumentando el número de las afectadas en muchos casos en proporción al tamaño de la población. Así, en las ciudades principales del Valle Central como Heredia (en su sector sur), Alajuela y San José, las fotos muestran y los reportes mencionan gran cantidad de daños, casas caídas y otras que obligaban a su demolición. No obstante, en estas últimas poblaciones, las casas bien construídas resistieron perfectamente el temblor principal y las réplicas principales.

Hay reportes que sugieren que el temblor fue percibido con mayor intensidad en la parte noreste del país. Por ejemplo, se mencionan daños en Toro Amarillo, Ciudad Quesada y Aguas Zarcas. Nuevamente, esto se explicaría por el relleno aluvial y lahárico sobre el cual se asientan estas localidades.

Un aspecto notable de destacar es que practicamente no se reportaron daños en Guanacaste. Esto indica que existió una rápida atenuación de las intensidades en la dirección noroeste del epicentro macrosísmico. Así, los lugares más lejanos en esta dirección donde se reportaron daños, fueron en la Isla de San Lucas y Puntarenas, a distancias epicentrales menores de $40 \mathrm{~km}$. La ausencia de daños importantes en Guanacaste puede ser explicada en buena parte, porque varias de las localidades de esta región, están ubicadas sobre un suelo rocoso o donde solo existe un pequeño espesor de depósitos aluviales sobre la roca (por ejemplo en Nicoya). También, la mayor atenuación de intensidades en esta región podría explicarla su ubicación cerca de un nodo en el patrón de radiación de la onda $\mathrm{S}$ asociada con la ruptura, que como veremos es de rumbo entre $\mathrm{N}$ y NE y con una importante componente sinestral.

\section{ACTIVIDAD SÍSMICA Y VOLCÁNICA DISPARADA POR EL TERREMOTO DE 1924}

Un aspecto de gran interés con respecto al terremoto de 1924, fue el efecto disparador de actividad sísmica y volcánica en las horas y días inmediatamente posteriores a la ocurrencia del sismo principal. Tenemos varias informaciones que permiten detallar este fenómeno. En una conferencia dictada por el Dr. Sapper a principios de abril de 1924, se describe que: “.. es sumamente probable que los retumbos observados $\mathrm{du}$ rante los ultimos temblores en Orotina, Turrubares, Puriscal, Santa Ana, Escazú, Esparta, Guayabo, Villa Colón, Piedras Negras pertenecen a esta clase..". Se refiere a retumbos de origen tectónico. Luego continua “..mientras que los retumbos que se hicieron oir en Llano Grande o en el Sanatorium del Irazú el 4 y el 11 de marzo eran de origen volcánico..". Más adelante agrega que: “..pero sabemos con seguridad, que los sismos tectónicos orotinenses han despertado a lo menos un foco volcánico, el del Irazú...”. Continúa indicando que "Don Emilio Robert ubicado en San Juan, en una finca situada en las faldas meridionales del volcán indicado, luego del terremoto de la 04:07 observó a las 4:30 de la mañana fuertes retumbos en Llano Grande y en el Sanatorio (pero no en San Juan) y a las cinco horas hizo el Irazú una erupción fuerte. Como a las 7 horas de la mañana se observó en San Juan otro temblor, pero de caracter absolutamente diferente: el movimiento no era ya en una sola dirección sino circular... Tales temblores de 
movimiento circular que son característicos en ciertos temblores volcánicos, se observaron en seguida muchas veces en San Juan. Luego se continua indicando que el 11 de marzo se notaron muchos choques sísmicos en San Juan y entre estos unos fuertes a las 10:30, 15 horas y 16 horas; el movimiento era horizontal. En Llano Grande se observó en la tarde del 11 además de ruídos subterráneos un temblor muy fuerte el cual superó en intensidad de los temblores que se notaron en Orotina y en la Altiplanicie demostrando con eso, que no dependía del foco orotinense, sino de otro que no puede ser otro que el del Irazú. Este volcán ha tenido erupciones algo grandes el 20, el 23 en la madrugada y el 31 de marzo (desde 4 a 6 a.m.) pero se había presentado tranquilo durante la presencia de la comisión antes del medio día del 23..”. (Diario de Costa Rica, 11 de abril de 1924, pág. 7).

En la anterior información debemos distinguir entre la sismicidad y el volcanismo disparado. Analicemos primero este último caso. Es claro que el terremoto del 4 de marzo disparó erupciones en el Irazú, posiblemente debido a que indujeron movimiento de magma residual. El volcán Irazú se localiza a unos 80 kilómetros de la zona de probable ruptura del terremoto de San Casimiro. Las erupciones del Irazú fueron confirmadas por varios observadores en diversas citas que aparecen en el Diario de Costa Rica. Un detalle del tipo de erupciones que tuvo el Irazú se da a raíz de la visita que realizaron al volcán alrededor del 23 de marzo, el Dr. Sapper en compañía entre otros del Prof. Fidel Tristán, este último luego reporta en el Diario de Costa Rica (26 de marzo) que: "las erupciones no son tan frecuentes como antes, pero salen vapores blancos que se desvanecen rápidamente, dejando un humo azul, que es ácido sulfúrico gaseoso..”. En contraposición a lo que ocurrió en el Irazú, los reportes mencionan que el volcán Poás se mantuvo inactivo.

Existe otro reporte sobre posible actividad volcánica asociada con este terremoto. En el Diario de Costa Rica (pág. 7 del 11 de abril de 1924), un corresponsal mencionó emanaciones volcánicas en el Rincón de la Vieja. Luego, el 25 de marzo en el mismo periódico, se transcribe un mensaje fechado 20 de marzo, proveniente del corresponsal de Liberia que dice: "En estos dias de agitaciones sísmicas el Rincón de la Vieja no ha querido quedarse atrás y quedó en un período de franca actividad, que no es natural por estos meses del año. En algunas de estas mañanas $y$ tardes, ha podido verse la columna de humo que sale de esta enorme chimenea..”. El volcán Rincón de la Vieja se localiza a una distancia cercana a los 140 kilómetros de la zona de Orotina.

Finalmente, el 10 de abril se menciona en el Diario de Costa Rica que están en erupción los volcanes Ometepe, Santiago, y Cerro Negro en Nicaragua y que se han sentido temblores en toda la costa del pacífico desde Granada hasta Corinto. Desafortunadamente, no se sabe si la actividad de los volcanes nicaraguenses fue posterior o anterior al terremoto del 4 de marzo, pero si es posterior podría también haber sido disparada por el terremoto del 4 de marzo, al igual que los temblores de la costa pacífica.

Stark \& Davis (1995) describen varios enjambres de microtemblores disparados en el campo geotérmico de los Geysers, California, por terremotos ocurridos a distancias de cientos y miles de kilómetros. Hill et al. (1993) describen los enjambres de temblores en el campo geotérmico de los Geysers, que siguieron al terremoto ocurrido en 1992 en Landers, California $(\mathrm{Mw}=7,3)$. Lo anterior, indica que fenómenos sismovolcánicos pueden ser disparados por terremotos mayores.

Aparte de la actividad volcánica ocurrida en el macizo del Irazú, destaca también que el terremoto del 4 de marzo disparó movimientos sísmicos que pudieron ser de tipo sismovolcánico o asociados con las fallas que existen en este volcán (Montero \& Alvarado, 1995), especialmente en aquellas que se encuentran más cercanas a Llano Grande y a San Juan.

El Dr. Sapper indica también que hubo temblores con retumbos y por lo tanto de foco superficial, en Turrubares, Puriscal, Santa Ana, Escazú, Esparta, Guayabo, Villa Colón y Piedras Negras (Fig. 9). Asimismo, el Prof. Fidel Tristán confirma actividad en fallas cerca de San José: "La observación que muestra de que los movimientos tendían a propagarse hacia San José esta confirmada. Hemos comparado nuestros registros sismológicos con los que inserta el Diario 
de Costa Rica y de esa comparación resulta que fueron más fuertes los temblores del martes (se refiere al 11 de marzo) en esa capital que en Orotina y en San Pablo de Turrubares..”. Lo anterior indica que varios de los temblores sentidos con retumbos fueron debidos a eventos disparados en diferentes fallas periféricas a la zona de ruptura del terremoto del 4 de marzo.

Gomberg (1996) indica que los temblores disparados pueden asociarse a esfuerzos y deformaciones dinámicas inducidas durante el pasaje de las ondas sísmicas o a esfuerzos y deformaciones estáticas asociadas con la ruptura cosísmica. También, considera que las deformaciones dinámicas explicarían los eventos disparados a distancias remotas, mientras que los sismos disparados a distancias cercanas pueden deberse a ambos tipo de deformaciones. En nuestro caso, las erupciones del volcán Rincón de la Vieja serían relacionadas con deformaciones dinámicas. Las del Volcán Irazú, asi como los temblores con retumbos ocurridos entre Orotina y ese volcán, es posible asociarlos con esfuerzos dinámicos y estáticos. Si consideramos el modelo de Stein et al. (1992) de los esfuerzos estáticos inducidos en el campo cercano por el terremoto de Landers de $1992(\mathrm{Mw}=7,3)$, ocurrido en una falla dextral de rumbo NNW y por otro lado el terremoto del 4 de marzo de 1924 se asocia con la falla Tárcoles, que es de tipo sinestral y de rumbo NE, entonces esperaríamos un incremento de esfuerzos estáticos en la continuación del sistema de falla Tárcoles al noreste de Orotina, en el sector del sistema de fallas de Escobal, Quebradas, Tornos y La Garita y otras fallas de rumbo similar a la falla Tárcoles como la falla Virilla o conjugadas a la falla Tárcoles y de movimiento dextral como el sistema de fallas de Picagres-San Antonio (Montero et al., 1991). También, se incrementarían los esfuerzos en el sistema de falla Barranca en su sección de rumbo paralelo a los Montes del Aguacate.

Un detalle interesante es que Puriscal, Guayabo, Villa Colón y Piedras Negras forman parte de la misma zona epicentral donde ocurrió la secuencia sísmica de mayo a junio de 1990, que luego culminó con el terremoto de Piedras Negras del 22 de diciembre de 1990 (Ms = 5,7) (Montero et al., 1991). Por lo tanto, es muy posible que el terremoto del 4 de marzo sobrecargó con esfuerzos adicionales y temporalmente adelantó la actividad sísmica de 1990, en la zona de fallamiento de Picagres-San Antonio-Virilla. Esta actividad sísmica fue finalmente disparada por el terremoto de Cóbano del 25 de marzo de $1990(\mathrm{Mw}=7,0)$ (Barquero et al., 1991; Protti et al., 1995b). Es interesante observar que este último terremoto y el de Limón del 3 de abril de $1991(\mathrm{Mw}=7,7)$ no dispararon actividad sísmica en lo que fue la ruptura de 1924, porque esta tuvo una importante caída de esfuerzos luego de este temblor y probablemente el período de recurrencia en esta fuente sismogénica sea del orden de cientos de años, porque no existe evidencia de terremotos históricos en este sistema de fallas (Peraldo y Montero, 1994).

Sismicidad disparada en Costa Rica fue previamente sugerida por Montero \& Alvarado (1988), quienes proponen que el terremoto de Bagaces del 6 de diciembre de $1941(\mathrm{M}=6,0)$ fue disparado por el terremoto del Golfo Dulce del 5 de diciembre de 1941 ( $M=7,5)$. Igualmente, se observó sismicidad en la zona periférica al área de ruptura y actividad volcánica en el Irazú disparada para el terremoto de Limón de 1991 (Barquero \& Rojas, 1994; Barquero et al., 1995).

\section{EFECTOS ELÉCTRICOS}

El Dr. Sapper reporta en una conferencia transcrita en el Diario de Costa Rica entre el 10 y 11 de abril que: “.. El señor Obispo don Agustin Blessing, observó en Amurero, cerca de Sipurio que se verificó en la madrugada de aquel día un temblor fuerte de intensidad V a VI. Un minuto después se oyeron enormes retumbos, parecidos en su vehemencia a la cañonada.. y se vieron grandísimas descargas eléctricas de abajo arriba y de arriba hasta abajo en dirección hacia el NO..". Amubri se encuentra al este de Costa Rica, cerca de la frontera con Panamá (Fig. 9), a unos 180 kilómetros de la zona de Orotina. La anterior observación puede deberse a una asociación entre el fenómeno eléctrico y el 
terremoto, aunque pocos casos han sido reportados en la literatura.

Otra interpretación posible es que las descargas eléctricas realmente representaran un fenómeno luminoso. Efectos luminiscentes han sido frecuentemente asociados con sismos debido a fenómenos piezoeléctricos que se desarrollan en el cuarzo (por ejemplo, Derr, 1973). Esta interpretación es posible porque el temblor ocurrió en la madrugada a las 4: 07 (H. L.). Yasui (1968) indica que estos fenómenos luminosos se observan frecuentemente en zonas donde hay cimas montañosas con rocas falladas de dioritas cuarzosas. Este es precisamente el ambiente geológico que se presenta en la Cordillera de Talamanca, donde existen gran cantidad de rocas intrusivas de tipo ácido a intermedio, ricas en cuarzo. Fenómenos luminosos también me fueron reportados por distintos observadores para el terremoto de Osa, Costa Rica del 3 de abril de $1983(\mathrm{Mw}=7,4)$. Estos fueron observados desde distintos sectores del Valle Central hacia la Cordillera de Talamanca.

\section{EFECTOS HIDROGEOLÓGICOS}

Existen en el Diario Costa Rica varios reportes de distintos lugares que sugieren que el terremoto provocó cambios en el movimiento de las aguas subterráneas (Fig. 9). Una nota indica que por el lado sur del Cerro Turrubares, las aguas de los riachuelos disminuyeron mientras que por el lado norte han aumentado de un 25 a un $30 \%$ de caudal. Otra nota del 15 de marzo proveniente de San Mateo indica: "Otro fenómeno que notamos es que habían muchas quebradas que no tenían absolutamente nada de agua, y que ahora corre como si estuvieramos en invierno, y en otras partes se han secado manantiales en los que nunca faltaba". De Desmonte de San Mateo se reporta el 29 de marzo: "En este lugar hay gran alarma por la escasez de agua. Hasta la vez todos teníamos medios para servirnos de este líquido, pero desde los últimos temblores, están secándose todas las quebradas de donde se proveía el pueblo...".
Finalmente, el 27 de marzo se describe en una nota que: "El martes, a las cuatro de la tarde, el Río María Aguilar mermó el caudal de sus aguas en doce centímetros, después de los temblores; más tarde a las cinco y media completó su curso natural de verano". Efectos hidrogeológicos han sido frecuentemente observados asociados con terremotos de magnitud alta.

\section{LA FUENTE SÍSMICA DEL TERREMOTO DE 1924}

Uno de los aspectos más relevantes sobre el terremoto de 1924, es dilucidar la fuente sísmica que originó este evento, lo cual es importante para la correcta evaluación de la amenaza sísmica de la región pacífico-central e incluso del Valle Central, asiento de la mayor población y de la principal infraestructura de Costa Rica. Para realizar este análisis, evaluamos las posibles fuentes sísmicas donde se pudo haber originado este terremoto, las cuales se pueden dividir en dos grandes grupos:

1.- $\quad$ Relacionadas con la subducción de la placa del Coco, donde tenemos tres alternativas:

a) El temblor se originó como resultado del movimiento interplaca Cocos-Caribe (o Cocos-microplaca Panamá). El plano de ruptura correspondería con una falla de bajocorrimiento. Una variación de esta propuesta es considerar que el evento rompió una aspereza relacionada con una montaña submarina acarreada por la placa del Coco a lo largo del plano de contacto con la placa superior (von Huene et al., 1995). En este caso la profundidad de la zona de ruptura debió ser inferior a los 40 $\mathrm{km}$, que corresponde al límite inferior de la zona frágil interplaca en Costa Rica (Protti et al., 1995a).

b) El sismo se originó dentro de la placa del Coco (temblor intraplaca). En este caso el evento debió tener una 
profundidad superior a los $40 \mathrm{~km} \mathrm{y}$ una profundidad máxima entre $70 \mathrm{y}$ $80 \mathrm{~km}$, en correspondencia con las profundidades que tiene la zona de Benioff bajo Orotina-San Mateo.

c) El temblor se originó en una discontinuidad transversal a la Fosa Mesoamericana localizada dentro de la placa del Coco (Stoiber \& Carr, 1973; Burbach et al., 1984; Protti et al., 1995a). La falla sería una falla de tipo tijera, con una fuerte componente de desplazamiento de rumbo.

2.- Relacionadas con el fallamiento cortical de la placa superior. Evaluamos tres diferentes opciones:

a) El temblor se originó en una frontera incipiente entre la placa Caribe y la microplaca de Panamá (Montero \& Dewey, 1982; Güendel \& Pacheco, 1992; Goes et al., 1993; Fan et al., 1993; Montero, 1994a; Fisher et al., 1994). La falla tendría desplazamiento de rumbo sinestral, aunque una componente de desplazamiento de inclinación importante podría esperarse (normal ?).

b) El temblor se originó en un segmento de la gran falla longitudinal de Costa Rica (falla Candelaria), de rumbo $\mathrm{N}$ $60^{\circ} \mathrm{W}$. La falla sería dextral con una componente de levantamiento.

c) El temblor se originó en una falla cortical ubicada en la placa superior, cuyo movimiento es inducido por la subducción de montañas submarinas por parte de la placa del Coco (Fisher et al., 1998).

Como vemos, existe un buen número de fuentes sísmicas y de modelos tectónicos alternativos para explicar el origen del terremoto de 1924. Para dilucidar entre las anteriores fuentes sísmicas, debemos tratar de ubicar el posible hipocentro de este evento. Para el caso del sismo interplaca relacionado con la subducción de la placa del Coco, este tendría una profundidad menor a $40 \mathrm{~km}$ y un área de ruptura bajo la zona marina. Un caso reciente de este tipo de eventos, fue el temblor de Cóbano del 25 de marzo de $1990(\mathrm{Ms}=7,0)$, el cual tuvo epicentro a la entrada del Golfo de Nicoya, en el área marina ubicada entre la Península de Nicoya y el promontorio de Herradura. De acuerdo con Protti et al. (1995b) este fue un sismo interplaca, cuyas réplicas fueron localizadas entre 15 y $25 \mathrm{~km}$. Sin embargo, aunque tuvo la misma magnitud que el terremoto de 1924, la zona de intensidad VIII que este evento generó dentro del área continental apenas alcanzó a afectar el sureste de la Península de Nicoya y el sector costero entre Puntarenas y Jacó y en la zona comprendida entre Esparza y Orotina, las intensidades observadas fueron de VII grados (Climent, 1991). Un evento interplaca un poco más grande ocurrido en esta zona fue el temblor del 21 de diciembre de 1939 (Ms = 7,3 ), el cual tampoco originó intensidades como las observadas para el terremoto de 1924. Por lo tanto, una fuente interplaca no parece explicar el origen del terremoto de 1924.

Igualmente, la propuesta de que el sismo se relacionó con una falla transversal a la Fosa Mesoamericana localizada dentro de la placa del Coco, se descarta si el hipocentro se localizó del lado marino (es decir, a la entrada del Golfo de Nicoya), porque al igual que en el caso anterior originaría intensidades menores que las observadas para el terremoto de 1924. Por lo tanto, el área de ruptura del terremoto de 1924 debió estar entre el área marina y la continental y predominantemente en esta última.

Es conveniente ahora definir la posible profundidad del evento de 1924. Esto para aclarar si el sismo fue cortical o puede ser considerado con una profundidad entre 40 y 70-80 km. Con relación a la profundidad existen algunos indicadores que señalan un hipocentro relativamente superficial. En primer lugar, las altas intensidades observadas entre VIII y IX grados dentro de la zona mesosísmica y que incluso muy localmente pudieron alcanzar hasta el grado X. Las mismas son concordantes con un sismo de profundidad somera. Igualmente, existen innumerables reportes de que los sismos réplica venían precedidos por retumbos. Por ejemplo, como vimos 
anteriormente, el Dr. Sapper mencionó: “Es sumamente probable que los retumbos observados durante los últimos temblores en Orotina, Turrubares, Puriscal ...sean de esta ultima clase”. Se refiere a retumbos de origen tectónico. El reporte de retumbos asociados con las réplicas del sismo de 1924, es un fuerte indicativo de que el mismo fue de origen superficial. Esto porque las ondas $\mathrm{P}$ son audibles al refractarse en la atmósfera, solo cuando la trayectoria de viaje de la onda entre la fuente y el observador es lo suficientemente corta, como para permitir que las altas frecuencias audibles no sean filtradas en su viaje entre el medio rocoso y el aire. El mapa de intensidades muestra un rápido decaimiento espacial de las intensidades, lo que también está de acuerdo con un foco somero. Finalmente, existe la sugerencia de que hubo una ruptura superficial asociada con el terremoto de 1924. Con base en lo anterior, podemos descartar las alternativas de una fuente sísmica de profundidad intermedia (entre 40 y $80 \mathrm{~km}$ ), quedando como única posibilidad de que el terremoto fue cortical. Tenemos varias posibles fallas con diferente mecanismo de ruptura que pudieron originar este terremoto. Entre estas estan las fallas Tárcoles, Bijagual, Barranca y la Candelaria. Veamos cual es la más viable de acuerdo con los datos recopilados.

\section{SELECCIÓN DE LA FALLA}

Tenemos varios tipos de informaciones independientes para escoger la posible falla que originó el terremoto de 1924, los cuales revisaremos seguidamente.

\section{Distancia epicentral y dirección epicentral con base en el evento principal y las réplicas}

Previamente vimos que los datos del Observatorio Nacional permiten estimar que los epicentros del evento principal y de las réplicas se localizaron entre el W y el SW, a distancias epicentrales entre 40 y $80 \mathrm{~km}$ con respecto a San
José (Fig. 9). Esta información restringe bastante las fallas donde se pudo originar el terremoto de 1924. Además, como vimos el evento principal, según la descripción del Observatorio Nacional, se localizó al WSW.

\section{Epicentro usando datos de estaciones sismológicas regionales}

En el reporte del ISS, la estación BHP fue la estación más cercana al epicentro. Las lecturas de $\mathrm{P}$ y $\mathrm{S}$ señalan un S-P entre 52 (componente NS) y 64 segundos (componente EW). Dado que BHP se ubica hacia el este del epicentro, la lectura en la componente NS (la de 52 segundos) es más confiable. Pero además, tenemos copia de una carta del Comandante de la Zona del Canal dirigida al Embajador de los Estados Unidos en Costa Rica, en donde se le reporta al Observatorio Nacional, que el temblor se localizó a unas 300 millas $(540 \mathrm{~km})$ de BHP. Hemos trazado un círculo con un radio de $4,9^{\circ}$ (equivale a $540 \mathrm{~km}$ ) alrededor de BHP en la figura 6 . Este radio pasa por la zona de Herradura. La siguiente estación con lecturas de $\mathrm{P}$ y S en el boletín del ISS es TAC, en México D. F. Su lectura de $\mathrm{S}-\mathrm{P}$ es de 3 minutos y 25 segundos, lo cual equivale a alrededor de $2140 \mathrm{~km}\left(19,3^{\circ}\right)$. Mis lecturas de $\mathrm{P}$ y S a partir de la copia del sismograma que tenemos coincide con las leídas entonces (ver Fig. 8). He trazado igualmente un círculo con el radio anterior para TAC, el cual se ubica sobre la zona fronteriza de Costa Rica y Panamá. Aunque las lecturas del Observatorio Nacional de El Salvador no fueron incorporadas en el ISS, hemos recopilado en el Diario de Costa Rica un par de informaciones sobre esta estación sismológica. Una nota del 19 de marzo dice: "El sismógrafo de San Salvador registró el temblor del cuatro.. a la altura de Puntarenas...". Más adelante, el 25 de marzo otra nota dice: "Hoy a las cuatro horas y nueve minutos fueron registrados en el Observatorio Sismológico de esta capital, dos largos movimientos sísmicos. Las distancias focales calculadas con las constantes de Omori y de Stiatessi oscilaron alrededor de 700 kilómetros". Esto equivale a 
un radio de 6,3 para esta estación (Fig. 6). Las dos estaciones sismológicas más cercanas al epicentro, que fueron BHP y la de San Salvador, muestran que sus círculos se cortan en la zona del promontorio de Herradura. Considerando los errores inherentes a estos cálculos, esto implicaría que el epicentro del sismo del 4 de marzo se ubicaría entre Herradura y Puntarenas.

\section{Relación de la falla con el mapa de intensidades}

En primer lugar, analizaremos el área mesosísmica del patrón de intensidades. Si superponemos el sistema de fallamiento y la zona mesosísmica (Fig. 12), vemos que podemos descartar la falla Barranca como la fuente del sismo de 1924, dado que un evento en esta falla habría generado muy altas intensidades en Puntarenas, Miramar y Esparza, lo cual no corresponde con lo observado, especialmente porque en las dos primeras poblaciones la intensidad observada fue VII, dos grados menor que la máxima intensidad determinada. Asimismo, se considera que las fallas Mata de Limón y Jesús María no fueron la fuente de este sismo, porque las máximas intensidades estan desplazadas hacia el E con respecto a las trazas de estas fallas. Igualmente, se pueden descartar las fallas Tulín y Candelaria, porque una ruptura en estas fallas con las características del sismo de 1924, habría generado intensidades más altas en el sector comprendido entre Puriscal y Quepos, aunque esta era una zona sumamente despoblada. Además, la zona mesosísmica del terremoto de 1924 se ubica al oeste de esta fallas. Lo anterior no implica descartar que algún evento réplica pudiera haber ocurrido en cualquiera de las fallas mencionadas.

Por lo tanto, quedan como alternativas para seleccionar la fuente del terremoto de 1924, el sistema de falla Tárcoles o el sistema de falla de Bijagual. En la figura 12, se muestra que ambos fallamientos se ubican dentro del área mesosísmica y son buenos candidatos para haber originado el sismo de 1924. Obsérvese que el patrón de isosistas tiene una cierta orientación NNE en la zona de mayor intensidad, aunque hay poca restricción hacia el sur de las isosistas en la zona donde se ubican las fallas de Bijagual, dado que

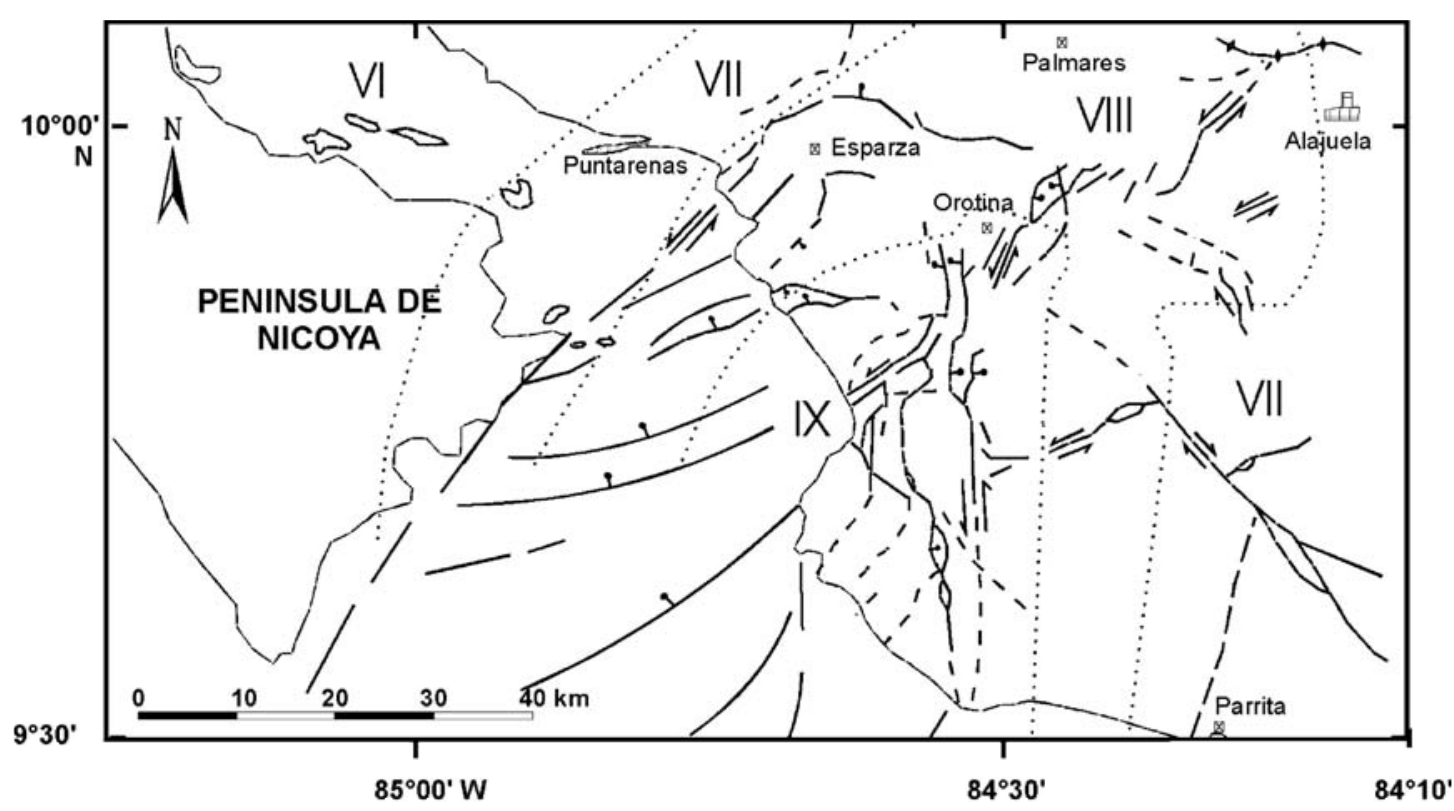

Fig. 12: Se superpone el sistema de fallamiento cortical del antearco central pacífico y las isosistas de intensidades mayores que VII del sismo principal. Obsérvese que los sistemas de fallas Tárcoles y Bijagual se localizan dentro del área de intensidad IX. 
era una región sumamente despoblada en 1924. Sin embargo, las pocas referencias que existen sobre observaciones macrosísmicas en esta región indican una intensidad del orden de IX. Por ejemplo, el Dr. Sapper en su conferencia dictada a principios de abril de 1924, menciona que “..si es cierto que los efectos de los temblores eran los más fuertes en Orotina y alrededores .. bién puede ser que el foco principal del movimiento sísmico principal se halle más al sur de Orotina, tal vez en la vecindad del mar pacífico, como lo parecen indicar los hechos observados en Herradura, Paquita y Quepos..”. Desafortunadamente lo ocurrido en Paquita y Quepos no es descrito en ningún documento recopilado; aún así como vimos, se pueden deducir altas intensidades al sur de Orotina, hacia Quepos, con base en los reportes provenientes de Herradura y Jacó. Además, una Comisión que viajó a la zona oeste del Cerro Turrubares, observó numerosos y algunos grandes deslizamientos en esta región.

\section{Probable ruptura superficial asociada}

Un terremoto de profundidad superficial de magnitud Ms = 7,0 como el de 1924, es un excelente candidato para originar una ruptura superficial. Aunque no se realizó inmediatamente después de este sismo una investigación geológica que permitiera documentar fidedignamente si ocurrió o no una ruptura superficial, si tenemos reportes periodísticos y hemos recopilado con testigos, informaciones que sugieren una posible ruptura superficial del terreno ocasionada por fallamiento. Por ejemplo, en el periódico La Tribuna se menciona que el señor Fernando Castro, quien tenía finca en Coyolar de Orotina: “..Informa que de fuente fidedigna le mencionan la existencia de una enorme grieta que partiendo del bajo de Capulin, casi en la desembocadura del Río Grande (de Tárcoles) atraviesa toda su finca y casi por una distancia de $15 \mathrm{~km}$ para ir a morir a un paraje cercano al Higuito en San Mateo". Aunque esta descripción es muy imprecisa en los detalles de la ubicación exacta de la grieta, si observamos que el Bajo del Capulín se encuentra a lo largo de la traza de la falla Tárcoles, mientras que Higuito de San Mateo se localiza al norte de una traza de falla de rumbo NS, que se ubica al norte de la intersección entre las fallas Tárcoles y Bijagual (sitio 5 en Fig. 4). La probable ruptura de la falla Tárcoles la he ubicado en la figura 9 con un trazo más grueso. Además, llama la atención que se exprese que la grieta tenía $15 \mathrm{~km}$ de largo. Aunque se desconoce que tan verídica puede ser esta estimación, he medido la distancia a lo largo de la trazas de las fallas Tárcoles y Bijagual, desde la hacienda Capulín hasta ligeramente al norte del poblado de Coyolar, donde la traza de falla es de rumbo N (Fig. 4) y he supuesto (aunque geomorfológicamente no se expresa), la continuación de esta traza con rumbo $\mathrm{N}$ hasta donde la grieta fue observada en la Finca La Rosita, cerca de Higuito, al oeste de San Mateo. Esa distancia es de $18 \mathrm{~km}$, distancia similar a la reportada en la nota periodística de 15 $\mathrm{km}$. De acuerdo con la relación entre la longitud de la ruptura $\mathrm{L}$ y la magnitud momento $\mathrm{Mw}$ deducida por Wells y Coppersmith (1994) para temblores de cualquier tipo de fallamiento:

$$
\mathrm{M}_{\mathrm{w}}=5,08+1,16 \log \mathrm{L}
$$

una falla de 15 a $18 \mathrm{~km}$ de largo, corresponde con un temblor de magnitud $\mathrm{Mw}=6,4$. Un temblor de $\mathrm{Mw}=7,0$, originaría una longitud de ruptura del orden de $45 \mathrm{~km}$. De lo anterior, se puede especular que la supuesta longitud de ruptura superficial reportada fue solo parte de una longitud de ruptura mayor que no fue observada porque ocurrió en zonas deshabitadas o en la zona marina.

Otro reporte sobre una posible zona de ruptura describe una grieta con una orientación diferente a la anterior. En el Periódico Alajuela en La Nación del 6 al 13 de abril de 1983 (pag 2D), don Julio Obando informa: "La otra es que la zanja que se abrió venía de las montañas norteñas de San Ramón, pasaba por Higuito de San Mateo en los llanos de la finca La Rosita, luego buscaba al sur, cruzaba como 400 metros al oeste de la quebrada de Guayabal, pasaba por Pozón, cogía los sitios de Pigres para morir en las grises arenas del mar". Obsérvese que en este caso nuevamente se habla que la grieta pasaba por Higuito de San Mateo, aunque como dije, en 
este sector la falla no se expresa geomorfológicamente. Vemos que la grieta continuó unos 400 metros al oeste de la quebrada Guayabal. De acuerdo con mi interpretación neotectónica, es en esta zona donde geomorfológicamente se observa el extremo norte de la traza de la falla Bijagual, luego de intersectarse con la falla Tárcoles (Fig. 4). En la zona de la quebrada Guayabal se forma una depresión anómala que orienta el drenaje al N. Un aparente escarpe se forma en el lado $\mathrm{W}$ de esta depresión, en una posición muy cercana a la descrita por el señor Obando. Se describe que la fractura seguía hacia Pozón, pasaba por los sitios de Pigres hasta morir en el mar. En esta zona de acuerdo con mi interpretación neotectónica, existe la traza Tivives que forma parte de la falla Tárcoles que pasa por los sitios de Pigres, y luego al este pasa al sur de la quebrada Pozón. Esta traza se une al este con la falla Tárcoles (Fig. 2).

Para confirmar las anteriores observaciones, se realizaron varias entrevistas con testigos que vivian en esta zona cuando ocurrió el terremoto de 1924. Esto incluyó una visita con el Sr. Obando a los sitios descritos por él. Diversos testigos corroboraron la grieta en la zona de la finca La Rosita (sitio 5 en Fig. 4). Además, varios describen una grieta pasando al este de la plaza de Coyolar y que dobló la línea del tren (sitio 3 en la Fig. 4). En el pueblo de Coyolar, se observaron importantes deformaciones en el suelo, cerca de la actual plaza de futbol (sitio 4 en Fig. 4). Esta ubicación de la grieta coincide con la ubicación de la traza de la falla Bijagual en este sector. Asimismo, un testigo nos habló de una grieta al este del poblado de Limonal (sitio 2 en Fig. 4), la cual se ubicaría bastante cerca de la localización de la traza de la falla Bijagual. Otro testigo reportó, al igual que el señor Obando, unas grietas por el lado de Pozón.

Lo anterior permite concluir que existe una fuerte sugerencia de que hubo una ruptura superficial de la falla Tárcoles y en parte de la falla Bijagual. Los datos aportados por diferentes testigos concuerdan en que esta ocurrió a lo largo de la traza de la falla Tárcoles desde la hacienda Capulín, hasta intersectar la falla Bijagual. Luego, parece que la ruptura siguió la falla
Bijagual, pasando al oeste de la quebrada Guayabal y extendiéndose hasta la finca La Rosita, aunque en este último sector la falla Bijagual no se expresa claramente en la geomorfología, porque posiblemente corresponde con la zona donde la falla pierde desplazamiento o su componente normal es muy pequeña. También, puede presumirse que la ruptura superficial reportada por el señor Obando y algunos otros testigos por el lado de Pozón y en los Bajos de Pigres, corresponde con otra ruptura en la falla Tivives o Bajamar, que forman parte del sistema de falla Tárcoles, que pudo ser simultánea con el evento principal o con alguna de las réplicas de mayor tamaño, las cuales alcanzaron magnitudes Ms entre 5,0 y 6,4. Además, una ruptura asociada con un sismo de esta última magnitud, puede alcanzar hasta $15 \mathrm{~km}$ de longitud.

Con relación a una posible ruptura superficial del sistema de falla Bijagual, al sur de su intersección con la falla Tárcoles, considero que esta sería casi imposible de documentar, dado que en 1924, esta era una zona sumamente despoblada.

\section{Mecanismo focal}

Un mecanismo focal realizado para este terremoto por Jacob et al. (1991), es de fallamiento transcurrente con una componente inversa (Fig. 1). Javier Pacheco (comunicación verbal, 1998) indica que el terremoto de 1924 es seguramente de desplazamiento de rumbo, y que la componente de desplazamiento de inclinación esta mal restringida, por lo que no puede confirmar una componente inversa o normal para este sismo. Los planos nodales son de rumbo NE con desplazamiento sinestral y de rumbo NW de desplazamiento dextral. Esta solución concuerda con que la fuente del terremoto de 1924 fue la falla Tárcoles, dado que su rumbo y tipo de desplazamiento apoyan la selección del plano nodal $\mathrm{NE}$ del mecanismo focal como el plano de ruptura. El plano nodal NW correspondería por ejemplo con un movimiento en la falla Candelaria, pero ningún dato apoya un deslizamiento cosísmico en la misma. 


\section{Tsunami o ola sísmica asociada}

Para este temblor no hay reporte de un tsunami en el catálogo de Iida et al. (1967) o en Cruz \& Wyss (1983). Sin embargo, en el Diario de Costa Rica (pág. 8 del 7 de diciembre de 1941) se reporta que "El año 1924 se acercaba a Puntarenas el vapor Acajutla y su capitán informó al llegar que lo sucedido a la altura de Herradura, le hizo pensar que encontraría destruído el puerto. Un movimiento sacudió la superficie del mar; la nave no andaba; parecía deslizarse hacia la profundidad. Tuvo la sensación de que el mar se hundia”. Esta observación se puede interpretar de dos formas diferentes: 1) Que en el barco se percibió un tsunami o 2) Una ola sísmica. Ambas posibilidades son viables porque el mecanismo de ruptura en la falla Tárcoles es consistente con una componente normal (Fisher et al., 1994; este trabajo), que podría originar desplazamiento del piso marino y disparar un tsunami. Una ola marina es también de esperar porque el barco Acajutla se ubicaba a la entrada del Golfo de Nicoya, dentro del área mesosísmica cuando ocurrió el temblor y la transmisión en el mar de ondas $\mathrm{P}$ de suficiente amplitud podían ser percibidas en un barco.

\section{SELECCIÓN DEL HIPOCENTRO DEL TERREMOTO DE 1924 Y DE SU SECUENCIA DE REPLICAS}

Existen dos determinaciones hipocentrales anteriores para este evento, que son la del ISS y la de Ambraseys (1995). La localización del ISS esta desplazada hacia el este, unos 50 a 60 $\mathrm{km}$ del área mesosísmica y por lo tanto se considera que esta localización es inapropiada para este sismo. Por otro lado, Ambraseys (1995) ubica el temblor en el piso oceánico entre la proyección de las trazas de la falla Tárcoles que se inician en la boca del Río Grande de Tárcoles y cerca del poblado costero de Tivives. Esta localización es bastante apropiada y sustancialmente mejor que la del ISS. Sin embargo, considero que esta se puede mejorar con base en el área mesosísmica del mapa de intensidades, el epicentro deducido con los datos de estaciones sismológicas regionales, la zona epicentral deducida del S-P de las réplicas y su dirección con respecto a San José y el conocimiento del fallamiento existente en la región afectada incluyendo una posible zona de ruptura. Entonces, combinaré estos diversos datos para obtener una mejor determinación de los parámetros focales del terremoto de 1924.

Considerando los diversos datos existentes concluyo que el terremoto de 1924 y algunas de sus principales réplicas ocurrieron en la falla Tárcoles y en el sistema de falla Bijagual. Sin embargo, prefiero seleccionar el hipocentro del evento principal directamente sobre la falla Tárcoles, con base en la posible zona de ruptura y el mecanismo focal. Como mencioné, un temblor de $\mathrm{Ms}=7,0$ puede originar una ruptura de alrededor de $45 \mathrm{~km}$ de largo. La longitud de la falla Tárcoles dentro del área continental es cercana a los $25 \mathrm{~km}$. Considerando que la extensión marina de la falla Tárcoles es la que se muestra en el mapa geológico de Fernández et al. (1997), entonces esta falla se continuaría mar adentro por una longitud adicional de varias decenas de kilómetros. Por lo tanto, es de esperar que una parte de la ruptura haya que ubicarla en la zona marina. No hay criterio especial para localizar el epicentro del temblor en uno u otro sector de la falla Tárcoles. Sin embargo, prefiero ubicarlo en el sector continental dado que es en esta zona donde existe una posible evidencia de una ruptura superficial de la falla. Por lo anterior, ubico el epicentro cerca de la Hacienda Capulín, en las coordenadas $9^{\circ} 50^{\prime}$ lat $\mathrm{N}$ y $84^{\circ} 35^{\prime}$ long W y la profundidad se estima en $15 \mathrm{~km}$. Esta última corresponde con la profundidad en que normalmente se inician las rupturas dentro de la zona frágil de la corteza. Además, es más precisa que la propuesta por Ambraseys (1995). En el cuadro 1 incorporo los datos de mi ubicación hipocentral.

Con respecto a las réplicas cuyas magnitudes fueron estimadas telesísmicamente (cuadro 1), considero que aunque para algunas se tienen reportes de intensidad, estas requieren un estudio especial para mejorar su posible ubicación. Sin embargo, algunos de estos eventos muy posiblemente 
ocurrieron en el sistema de falla segmentado que es continuación de la falla Tárcoles al este de Hacienda Vieja y que se presenta sobre la margen norte del Río Grande de Tárcoles, zona de los Montes del Aguacate, como serían las fallas Escobal, Tornos, Guácimos, Quebradas y La Garita. Incluso, es muy posible que el sistema de fallas de Puriscal (Picagres, San Antonio) y Virilla (Montero et al., 1991), que puede extenderse hasta San Antonio de Belén, haya sido epicentro de algunas de las réplicas sentidas. También, es posible que algunas de las réplicas de mayor magnitud ocurrieron a lo largo del sistema de falla Bijagual, considerando la interacción entre ambas fallas y que ambas forman parte del límite oriental de una cuenca de tracción. De hecho, parte de la ruptura debió ocurrir en el extremo norte de este último sistema de falla.

\section{SIGNIFICADO TECTÓNICO DEL TERREMOTO DE 1924}

Existen varias posibles explicaciones para el origen tectónico de este sismo. Fisher et al. (1998) propusieron que este tipo de eventos se pueden relacionar con esfuerzos inducidos dentro de la corteza de la placa cabalgante relacionados con la subducción de montañas submarinas por parte de la placa del Coco. Aunque este es un proceso tectónico plausible, nos parece que este tipo de deformación podría ocurrir directamente arriba de la zona interplaca y menos probable sobre la zona intraplaca, como corresponde con la ubicación en el sector continental de los sistemas de falla Bijagual y Tárcoles; este último se extiende posiblemente hasta la falla La Garita. Bajo esta región, la zona de subducción esta muy profunda como para esperar un efecto de las montañas submarinas sobre la placa cabalgante. Por otro lado, el sistema de falla Tárcoles (Fig. 2), constituye un sistema de falla continuo que se puede seguir desde la Fosa Mesoamericana, pasando por el Valle Central Occidental y continuarse con otras fallas hasta el sector caribe de Costa Rica (Fisher et al., 1994; Montero, 1994a).
Especialmente, Montero (1994a; en preparación) muestra en detalle como esta falla forma parte de una zona de deformación que incluye un sistema complejo de fallas, que es el límite incipiente entre la placa Caribe y la microplaca de Panamá. Este modelo tectónico me parece más viable, por lo que aquí propongo que el sismo del 4 de marzo de 1924 y su secuencia de réplicas, se relacionó con el límite incipiente entre los anteriores dos bloques tectónicos. Esto concordaría con los modelos propuestos por Goes et al. (1993), Fan et al. (1993) y Fisher et al. (1994), entre otros autores. Con este sistema de falla se relacionó el terremoto de Limón del 3 de abril de 1991 (Mw = 7,7), el cual como Goes et al. (1993) mostraron tiene un vector deslizamiento que corresponde con el probable movimiento entre la placa Caribe y la microplaca de Panamá (Fig. 1).

La existencia de un límite incipiente entre la microplaca Panamá y la placa Caribe a través de la región central de Costa Rica ha sido refutado recientemente por Fernández (1996), quién considera que no existen evidencias geológicas, sismológicas ni sismotectónicas que apoyen el mismo. Sin embargo, Fernández (1996) estudia solo la región central de Costa Rica y no incluye en su análisis fallas como la Barranca, el sistema de falla Tárcoles, Bijagual y sus relaciones con otras fallas de la región central, norte y caribe del país. Además, el mapa de fallamiento que muestra incluye fallas provenientes de diferentes fuentes de información, varias de las cuales no son neotectónicas. Asimismo, fallas sinestrales importantes como la falla Navarro o inversas como la falla Alajuela no son evaluadas dentro del análisis. En Montero (en preparación) se darán más argumentos en favor del modelo del límite incipiente placa Caribe-microplaca de Panamá.

\section{CONCLUSIONES}

Considerando diferentes evidencias como son la zona donde se originaron las réplicas y la dirección de estas con respecto a San José, un epicentro localizado con estaciones regionales, 
una posible zona de ruptura, la relación entre el fallamiento y la zona mesosísmica y un mecanismo focal, existe la fuerte sugerencia de que el terremoto de 1924 se originó en la falla Tárcoles, aunque también se considera que el sistema de falla Bijagual participó en el proceso de rupturas que caracterizó al evento principal y las réplicas principales. La posible interacción entre ambos sistemas de fallas es tectónicamente viable considerando que ambas forman parte del límite oriental de un sistema de fallamiento sinestral asociado con estructuras transtensivas. Este sistema de fallas que existen en el antearco central pacífico de Costa Rica, forma parte de un zona caracterizada por un intenso fallamiento cortical, que se localiza encima de la zona de convergencia de placas y que es parte de un límite difuso, que existe entre la placa del Caribe y la microplaca de Panamá. Este límite difuso está caracterizado al occidente por fallamiento sinestral con una componente normal importante. Ambos se relacionan con el movimiento de escape hacia el este de la microplaca de Panamá, generando tracción en la parte trasera oeste y compresión hacia el sector este (zona del Cinturón Deformado del Norte de Panamá). Por consiguiente, el terremoto de 1924 tiene un significado tectónico importante, dado que se considera un evento interplaca originado en el límite incipiente que existe entre los dos anteriores bloques tectónicos. Tomando en consideración su magnitud (Ms $=7,0$ ), su profundidad superficial y su ubicación al oeste de la región más densamente poblada de Costa Rica, este tipo de eventos presentan una alta amenaza sísmica para la región del pacífico central del país.

\section{AGRADECIMIENTOS}

Esta investigación fue financiada por la Vicerrectoria de Investigación bajo el número de proyecto No 113-96-306, a quienes agradecemos el apoyo logístico recibido. Agradecimiento a Héctor Flores, Raúl Arias, Ricardo Cascante, Wilfredo Rojas y Mario Fernández, quienes dieron apoyo en el campo. Muy especial agradecimiento a Sergio Rojas quien se esmero en la realización de las figuras de este artículo. Un muy caluroso apoyo fue recibido de todo el personal del Cuerpo de Bomberos de Orotina, en especial de Daniel Moscoso y de Hernán Azofeifa. A todos ellos les expreso mi más cordial agradecimiento por toda la colaboración y atenciones recibidas. Finalmente, se agradece a los dos árbitros que ayudaron a mejorar el texto.

\section{REFERENCIAS}

ABE, K., 1981: Magnitudes of large shallow earthquakes from 1904 to 1980 . - Phys. Earth Planet. Inter., 27: 72-93.

AMBRASEYS, N. N., 1995: Magnitudes of Central American earthquakes 1898-1930. - Geophys. J. Int., 121: 545-556.

ARIAS, O. \& DENYER, P., 1991: Estructura geológica de la región comprendida en las hojas topográficas Abra, Caraigres, Candelaria y Río Grande, Costa Rica. - Rev. Geol. Amer. Centr., 12: 61-74.

ASTORGA, A., FERNÁNDEZ, J. A., BARBOZA, G., CAMPOS, L., OBANDO, J., AGUILAR, A. \& OBANDO, L. G., 1991: Cuencas sedimentarias de Costa Rica: Evolución geodinámica y potencial de hidrocarburos. - Rev. Geol. Amer. Centr., 13: 25-60.

BARBOZA, G., BARRIENTOS, J. \& ASTORGA, A., 1995: Tectonic evolution and sequence stratigraphy of Central Pacific Margin of Costa Rica. - Rev. Geol. Amer. Centr., 18: 43-64. 
BARQUERO, R., MONTERO, W. \& ROJAS, W., 1991: Actividad sísmica relacionada con el sismo de Cóbano. -La Crisis Sísmica del Golfo de Nicoya y eventos sísmicos relacionados, Costa Rica, 1990. - Informe del Instituto Costarricense de Electricidad, Dirección de Ingeniería Civil, Departamento de Geología, Capítulo 4: 45-73.

BARQUERO, R., LESAGE, P., METAXIAN, J. P., CREUSOT, A. \& FRENÁNDEZ, M., 1995: La crisis sísmica en el volcán Irazú en 1991 (Costa Rica). - Rev. Geol. Amer. Centr., 18: 5-18.

BARQUERO, R. \& ROJAS, W., 1994: Sismicidad inducida por el terremoto de Limón. Rev. Geol. Amer. Centr., Volumen Especial Terremoto de Limón 22 de abril de 1991: 111-120.

BURBACH, G.V., FROHLICH, C., PENNINGTON, W. D. \& MATUMOTO, T., 1984: Seismicity and tectonics of the subducted Cocos Plate. - J. Geophys. Res., 89: 7719-7735.

CLIMENT, A., 1991: Observaciones macrosísmicas y aceleraciones, en la crisis sísmica del Golfo de Nicoya y eventos sísmicos relacionados, Costa Rica, 1990. - Informe del Instituto Costarricense de Electricidad, Dirección de Ingeniería Civil, Departamento de Geología, Capítulo 2, 15-33.

CORRIGAN, J., MANN, P.\& INGLE, J. C., 1990: Forearc subduction of the Cocos ridge, Panama-Costa Rica. - Geol. Soc. Amer. Bull., 102: 628-652.

CRUZ, G. \& WYSS, M., 1983: Large earthquakes, mean sea level, and tsunamis along the Pacific coast of Mexico and Central America. - Bull. Seism. Soc. Am., 73: 553-570.

DENGLER, L. \& MCPHERSON, R., 1993: The 17 August 1991 Honeydew earthquake, North Coast California: A case for revising the Modified Mercalli scale in sparsely populated areas. - Bull. Seism. Soc. Am., 83: 1081-1094.

DERR, J. S., 1973: Earthquake lights: A review of observations and present theories. Bull. Seism. Soc. Am., 63: 2177-2187.

DONDOLI, C., DENGO, G. \& MALAVASSI, E., 1968: Mapa Geológico de Costa Rica, Escala 1: 1.500.000. - Dirección de Geología y Minas, San José.

DUDA, S., 1965: Secular seismic energy release in the Circum-Pacific belt. - Tectonophysics, 2: 409-452.

FAN, G., BECK, S. \& WALLACE, T., 1993: The seismic source parameters of the 1991 Costa Rica aftershock sequence: Evidence for a transcurrent plate boundary. - J. Geophys. Res., 98: 15759-15778.

FERNÁNDEZ, M., 1995: Análisis sísmico en la parte central de Costa Rica y evaluación del hipotético sistema de falla transcurrente de Costa Rica. - Tésis de Maestría, Instituto de Geofísica, Universidad Nacional Autónoma de México, 85 págs. +1 apéndice.

FERNÁNDEZ, M., 1996: Evaluación del hipotético sistema de falla transcurrente esteoeste de Costa Rica. - Rev. Geol. Amer. Centr., 19/20: 57-74. 
FERNÁNDEZ, J. A., AGUILAR, A., ARRIETA, T., ASTORGA, A., BARBOZA, G., BARRIENTOS, J., BARBOZA, X., BOTAZZI, G., BUSTOS, I., CALVO, C., CAMPOS, L., ESCALANTE, G., LAURITO, C., OBANDO, J., PIZARRO, D., ROJAS, J. F., TEJERA, R., VALERIN, E. \& VALERIO, A., 1997: Mapa geológico de Costa Rica. - Ministerio del Ambiente y Energia y Refinadora Costarricense de Petróleo, escala 1: 750000 .

FISCHER, R., 1980: Recent tectonic movements of the Costa Rican Pacific coast. Tectonophysics, 70: T25-T33.

FISHER, D. M., GARDNER, T. W., MARSHALL, J., \& MONTERO, W., 1994: Kinematics associated with the late Cenozoic deformation in Central Costa Rica: Western boundary of the Panama microplate. - Geology, 22: 263-266.

FISHER, D. M., GARDNER, T. W., MARSHALL, J., SAK, P. B. \& PROTTI, M. 1998: Effect of subducting sea-floor roughness on fore-arc kinematics, Pacific coast, Costa Rica. - Geology, 26: 467-470.

GOES, S., VELASCO, A., SCHWARTZ, S. \& LAY, T., 1993: The April 22, 1991, Valle de la Estrella, Costa Rica $(\mathrm{Mw}=7,7)$ earthquake and its tectonic implications: A broadband study. - J. Geophys. Res., 98: 8127-8142.

GOMBERG, J., 1996: Stress/strain changes and triggered seismicity following the Mw 7,3 Landers, California, earthquake. - J. Geophys. Res., 101: 751-764.
GÜENDEL, F. \& PACHECO, J., 1992: The 1990-1991 seismic sequence across central Costa Rica: evidence for the existence of a micro-plate boundary connecting the Panama deformed belt and the Middle America Trench (abs). - EOS, Transactions American Geophysical Union, 73: 399.

GÜENDEL, F., MONTERO, C., GONZÁLEZ, V., SEGURA, J. \& BRENES, J., 1992: Actividad sísmica de caracter superficial registrada por la red sismográfica del OVSICORI-UNA en la hoja San José 1:200.000 entre abril 1984-julio 1988. Rev. Geogr. Amer. Centr., 25-26: 11-44.

GÜENDEL, F., MONTERO, C., ROJAS, D., BRENES, J., SEGURA, J., SAÉNZ, R. \& GONZÁLEZ, V., 1993: Informe sobre el enjambre sísmico ocurrido cerca de la ciudad de Orotina entre el 21 y el 24 de enero de 1989, Catálogo de temblores 1989. Instituto de Investigación Observatorio Vulcanológico y Sismológico de Costa Rica, OVSICORI, Universidad Nacional, 147-152.

GUTENBERG, B. \& RICHTER, C. H., 1954: Seismicity of the Earth and associated phenomena. - Princeton University Press, second edition, 310 págs.

GUTENBERG, B. \& RICHTER, C. H., 1956: Earthquake magnitude, intensity, energy and acceleration (second paper). - Bull. Seism. Soc. Am., 46: 105-145.

HILL, D. P., et al., 1993: Seismicity remotely triggered by the magnitude 7.3 Landers, California earthquake. - Science, 260: 1617-1623. 
IIDA, K., COX, D. C. \& PARARAS-CARAYANNIS, G., 1967: Preliminary Catalog of Tsunamis ocurring in the Pacific Ocean. - Data Report No.5, preparado para el Estado de Hawaii y la Office of Naval Research, 131 págs.

JACOB, K., PACHECO, J. \& SANTANA, G., 1991: Seismology and Tectonics, en Costa Rica Earthquake of April 22, 1991: Reconnaissance Report. - Earthquake Spectra, Supplement B to Vol. 7: 15-33.

LONSDALE, R. \& KLITGORD, K., 1978: Structure and tectonic history of the eastern Panama Basin. - Geol. Soc. Am. Bull., 89: 981-999.

MADRIGAL, R., 1970, Geología del mapa básico Barranca, Costa Rica. - Informe Técnico IX (37), Ministerio de Energía, Industria y Comercio, San José, Costa Rica, 59 págs.

MARSHALL, J., 1994: Evolution of the Orotina fan, Pacific coast, Costa Rica: Late Cenozoic tectonism along the western boundary of the Panama microplate. Geol. Soc. Am. Abstracts with programs, 26: A 207.

MONTERO, W., 1986: Períodos de recurrencia y tipos de secuencias sísmicas de los temblores interplaca e intraplaca en la región de Costa Rica. - Rev. Geol. Amer. Centr., 5: 35-72.

MONTERO, W., 1989: Sismicidad histórica de Costa Rica 1638-1910. - Geofis. Inter., 28: 531-559.
MONTERO, W., 1994a: Neotectonics and related stress distribution in a subductioncollisional zone: Costa Rica. - En SEYFRIED \& HELLMANN: Geology of an evolving island arc: southeastern Central America.- Profil, 7: 125-141.

MONTERO, W., 1994b: Sismicidad y neotectónica. - En: DENYER \& KUSSMAUL: Atlas Geológico Gran Area Metropolitana. - Editorial Tecnológica de Costa Rica, Cartago, 147-160.

MONTERO, W., en preparación: Neotectónica de la región central de Costa Rica: Frontera oeste de la microplaca de Panamá.

MONTERO, W., \& ALVARADO, G., 1988: Los terremotos de Bagaces de 1935 y 1941: Neotectonismo transversal a la Cordillera Volcánica del Guanacaste. - Ciencia \& Tecnología, 12: 69-87.

MONTERO, W. \& ALVARADO, G., 1995: El terremoto de Patillos del 30 de diciembre de $1952(\mathrm{Ms}=5,9)$ y el contexto neotectónico de la región del volcán Irazú, Costa Rica. - Rev. Geol. Amer. Centr., 18: 25-42.

MONTERO, W., BOSCHINI, I. \& ROJAS, W., 1991: El terremoto de Cóbano, Costa Rica, 25 de marzo de 1990. En: La Crisis Sísmica del Golfo de Nicoya y eventos sísmicos relacionados, Costa Rica, 1990. Departamento de Geología, Instituto Costarricense de Electricidad, 1-14.

MONTERO, W. \& DEWEY, J. W., 1982: Shallow-focus seismicity, composite focal mechanism, and tectonics of the Valle Central, Costa Rica. - Seism. Soc. Am. Bull., 71: 1611-1626. 
MONTERO, W., ROJAS, W., BOSCHINI, I., BARQUERO, R. \& FLORES, H., 1991: Neotectónica de la región de Puriscal. Origen de la sismicidad de mayo-diciembre de 1990. - Memorias $5^{\circ}$ Seminario Nacional de Geotécnia-Ier Encuentro Centroamericano de Geotecnistas: 4.38-4.51.

MONTERO, W., ROJAS, W., FERNÁNDEZ, M., BRENES, L. F. \& REDONDO, C., en preparación: Sismicidad y sismotectónica de la región central de Costa Rica.

PERALDO, G. \& MONTERO, W., 1994: Terremotos coloniales de Costa Rica. - 162 págs., Editorial Tecnológica de Costa Rica, Cartago.

PROTTI, M., GÜENDEL, F.\& MCNALLY, K., 1995a: Correlation between the age of the subducting Cocos plate and the geometry of the Wadati-Benioff zone under Nicaragua-Costa Rica, en P. MANN, ed., Geologic and Tectonic development of the Caribbean plate boundary in Southern Central America. - Geol. Soc. Amer Special Paper 295: 309-326.

PROTTI, M., MCNALLY, K., PACHECO, J., GONZáLEZ, V., MONTERO, C., SEGURA, J., BRENES, J., BARBOZA, V., MALAVASSI, E., GÜENDEL, F., SIMILA, G., ROJAS, D., VELASCO, A., MATA, A. \& SCHILLINGER, W., 1995b: The March 25, $1990\left(\mathrm{M}_{\mathrm{W}}=7.0 \mathrm{M}_{\mathrm{L}}=6.8\right)$, earthquake at the entrance of the Nicoya Gulf, Costa Rica: Its prior activity, foreshocks, aftershocks, and triggered seismicity. - J. Geophys. Res., 100: 2034520358.

PROTTI, R., 1996: Monitoreo de desplazamientos a lo largo de la falla La Garita (Costa Rica) entre marzo y diciembre de 1990. Rev. Geol. Amer. Centr., 19/20: 183-185.
SAK, P., FISHER, D., GARDNER, T. W., PROTTI, M. \& MARSHALL, J., 1997: Recent landscape evolution and fault kinematics related to basement-exposed blocks, Pacific coast, Costa Rica. - Geol. Soc. Amer. Abstracts with programs, A-442.

STARK, M. A. \& DAVIS, S. D., 1995: Remotely triggered microearthquakes at the Geysers geothermal field, California. - Geophys. Res. Lett.

STEIN, R. S., KING, G. C. P. \& LIN, J., 1992: Change in failure stress on the southern San Andreas fault system caused by the 1992 magnitude $=7.4$ Landers earthquake. - Science, 258: 1328-1332.

STOIBER, R. \& CARR, M., 1973: Quaternary volcanic and tectonic segmentation of Central America. - Bull. Volcanol., 37: 304-325.

TOPPOZADA, T. K., 1975: Earthquake magnitude as a function of intensity data in California and Western Nevada. - Bull. Seism. Soc. Am., 65: 1223-1238.

TRISTÁN, F., 1911: Notas sobre el terremoto de Guatuso, 10 de octubre de 1911. - Anales del Centro de Estudios Sismológicos de Costa Rica, Tipografía Nacional, San José, Costa Rica, 47-51.

YASUI, Y., 1968: A study of luminous phenomena accompanied with earthquakes (part I). Mem. Kakioka Mag. Obs., 13: 25-61.

VON HUENE, R., BIALAS, J., EMEIS, K., FLUH, E., LEANDRO, C., CROPP, B., CSERNOK, T., FABEL, E., PEREZ. I., 
FLORES, A., HOFFMANN, J., HOLLER, P., LEON, R., BARRIOS, O., CHAVARRIA, J., JESCHKE, G. \& ESCOBEDO, D., 1995: Morphotectonics of the Pacific Convergent Margin of Costa Rica, Geologic and Tectonic development of the Caribbean plate boundary in Southern Central America. - Geol. Soc. Amer. Spec. Paper 295: 291-307.
WELLS, D. L. \& COPPERSMITH, K. J., 1994, New empirical relationships among magnitude, rupture length, rupture width, rupture area, and surface displacement. Bull. Seism. Soc., Am., 84: 974-1002.

WEYL, R., 1961: Die Geologie Mittelamerikas. - 226 págs., Borntraeger, Berlin. 